\section{Amilorides inhibit SARS-CoV-2 replication in vitro by targeting RNA structures}

\author{
Martina Zafferani ${ }^{1} \dagger$, Christina Haddad $^{2} \dagger$, Le Luo $^{2} \ddagger$, Jesse Davila-Calderon ${ }^{2} \ddagger$, Liang-Yuan Chiu ${ }^{2} \ddagger$, \\ Christian Shema Mugisha ${ }^{3}$, Adeline G. Monaghan ${ }^{1}$, Andrew A. Kennedy ${ }^{4}$, Joseph D. Yesselman ${ }^{5}$, \\ Robert J. Gifford ${ }^{6}$, Andrew W. Tai ${ }^{4}$, Sebla B. Kutluay ${ }^{3}$, Mei-Ling Li $^{7 *}$, Gary Brewer ${ }^{7 *}$, \\ Blanton S. Tolbert ${ }^{2 *}$, Amanda E. Hargrove ${ }^{1 *}$
}

\begin{abstract}
The SARS-CoV-2 pandemic, and the likelihood of future coronavirus pandemics, emphasized the urgent need for development of novel antivirals. Small-molecule chemical probes offer both to reveal aspects of virus replication and to serve as leads for antiviral therapeutic development. Here, we report on the identification of amiloride-based small molecules that potently inhibit OC43 and SARS-CoV-2 replication through targeting of conserved structured elements within the viral 5 '-end. Nuclear magnetic resonance-based structural studies revealed specific amiloride interactions with stem loops containing bulge like structures and were predicted to be strongly bound by the lead amilorides in retrospective docking studies. Amilorides represent the first antiviral small molecules that target RNA structures within the $5^{\prime}$ untranslated regions and proximal region of the CoV genomes. These molecules will serve as chemical probes to further understand CoV RNA biology and can pave the way for the development of specific CoV RNA-targeted antivirals.
\end{abstract}

\section{INTRODUCTION}

Severe acute respiratory syndrome coronavirus 2 (SARS-CoV-2) is the etiological agent of the COVID-19 respiratory disease, the largestscale respiratory virus pandemic the world has witnessed since the 1918 Spanish flu and that has claimed more than 3.9 million lives worldwide as of July $2021(1-3)$. Coronaviruses (CoVs) generally cause mild flu-like symptoms in humans but have caused two smaller-scale pandemics in the last two decades: SARS-CoV (2003) and MERS (2012) (4). Recent phylogenetic mapping traced all human $\mathrm{CoVs}$ to animal origins (5). While the middle zoonotic carrier of the virus between the animal of origin and humans seems to vary between CoVs, the chronological surfacing of human $\mathrm{CoV}$ pandemics seems to follow a dangerous trend of increasing lethality of each pandemic, thereby underscoring the need for a better understanding and targeting of the current and future $\mathrm{CoV}$ etiologic agents.

After more than a year since the first cases of SARS-CoV-2 human infection, this virus is expected to remain a global threat until vaccines are available and adopted worldwide. Furthermore, despite the increase in number of approved vaccines, their implementation has been hindered by the scarcity of doses available worldwide. On top of the production rate, pharmaceutical companies are currently facing challenges with the recently reported SARS-CoV-2 variants, against which not all vaccines have proven sustained efficacy, highlighting

\footnotetext{
${ }^{1}$ Chemistry Department, Duke University, 124 Science Drive, Durham, NC 27705, USA. ${ }^{2}$ Department of Chemistry, Case Western Reserve University, Cleveland, $\mathrm{OH} 441106$, USA. ${ }^{3}$ Department of Molecular Microbiology, Washington University School of Medicine, Saint Louis, MO 63110, USA. ${ }^{4}$ Department of Internal Medicine and Department of Microbiology and Immunology, University of Michigan, 1150 W Medical Center Dr., Ann Arbor, MI 48109, USA. ${ }^{5}$ Department of Chemistry, University of Nebraska-Lincoln, Lincoln, NE 68588, USA. ${ }^{6}$ MRC-University of Glasgow Centre for Virus Research, 464 Bearsden Rd., Bearsden, Glasgow G61 1QH, UK. 'Department of Biochemistry and Molecular Biology, Rutgers Robert Wood Johnson Medical School, 675 Hoes Lane West, Piscataway, NJ 08854, USA.

*Corresponding author. Email: lime@rwjms.rutgers.edu (M.-L.L.); brewerga@rwjms. rutgers.edu (G.B.); bst18@case.edu (B.S.T.); amanda.hargrove@duke.edu (A.E.H.) tCo-first authors.

¥Co-second authors.
}

the need for a synergistic antiviral-based approach (6). While recent treatments have been approved for use within hospital settings, there are no known U.S. Food and Drug Administration (FDA)-approved cures for the infection (7).

Current candidates for treatment have limited approval for emergency use in severe COVID-19 cases. Remdesivir, for example, is an RNA-dependent RNA polymerase inhibitor (RdRp) initially developed during the Ebola outbreak and revisited at the start of the pandemic (8). The compassionate use of the candidate antiviral across many countries reported mixed results, with overall faster recovery time from the virus but no difference in mortality rates (9). While more randomized trials are needed for a final verdict on the efficacy of remdesivir in critical patients, its stereospecific multistep synthetic process highlights the need for new, scalable, and more efficacious antivirals. Baricitinib has been recently approved for emergency use for COVID-19 treatment in conjunction with remdesivir. Also known as Olumiant, this small molecule was approved in 2018 as treatment for moderate to severe rheumatoid arthritis (10). It is proposed that the anti-inflammatory effects of the drug help in decreasing inflammatory cascades associated with COVID-19. While promising, baricitinib has yet to receive approval as a stand-alone treatment and, so far, has been shown to improve recovery time by 1 day when compared with remdesivir-alone treatment (7).

The recent emergence of multiple coronavirus pandemics clearly indicates that SARS-CoV-2 most likely will not be the last CoV pandemic (4). The current limited tools and lack of cures underscore the need for a new approach in developing antivirals that would not only provide novel routes to combat the current pandemic but also provide invaluable information on targetable structures that can aid in the prevention of and fight against future $\mathrm{CoV}$ outbreaks. Small molecules are uniquely poised to achieve this goal as their design and development provide both a better understanding of $\mathrm{CoV}$ biology and identify druggable targets that could aid in the development of pan-coronavirus antivirals.

Several steps in the coronavirus replication cycle offer potential therapeutic targets for viral inhibition (Fig. 1). CoVs are enveloped 


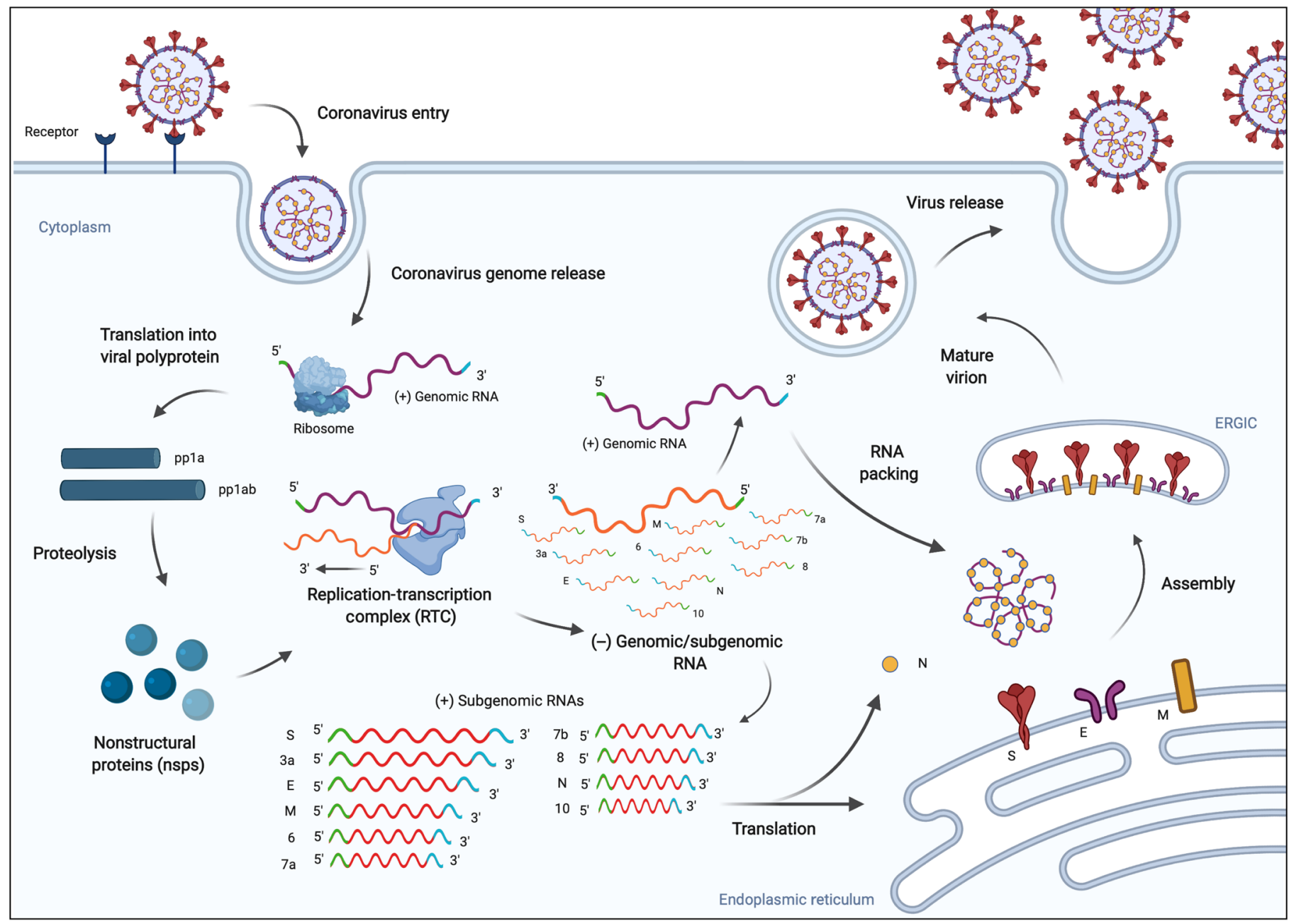

Fig. 1. SARS-CoV-2 replication cycle (56). The virus enters human cells via endocytosis by binding the ACE2 receptor and releasing its positive-sense RNA genome. The virus exploits the host machinery to facilitate efficient viral replication, which ultimately leads to progression of infection (57).

positive-sense single-stranded RNA genomes of approximately 30 kilobases, making them the largest genomes of RNA viruses (4). SARS-CoV-2 infects human cells by engagement of the ACE2 receptor by the viral spike (S) protein followed by membrane fusion at the plasma membrane or endosomal membranes depending on the availability of host cell proteases that cleave and prime $\mathrm{S}$ for entry. Fusion results in the release of its genome and associated proteins in the host cell cytosol. The genome is translated into two large polyproteins, $1 \mathrm{a}$ and $1 \mathrm{~b}$, which are then processed into individual proteins by the viral protease. Synthesis of full-length negative-strand RNA by products of $1 \mathrm{a} / 1 \mathrm{~b}$ creates a template to synthesize multiple positive strand copies encapsidated by the viral nucleoprotein into virions (4). The negative RNA strand also serves as a template for the synthesis of shorter subgenomic RNAs that include the essential structural proteins and thus also constitute an attractive therapeutic target (11).

$\mathrm{CoV}$ antivirals to date have been developed to target viral proteins, including to prevent endocytosis, assembly of viral protein for export, and condensation of viral genome for packaging (12). While this protein-centric approach has been proven successful in a few cases, the sequence and structural conservation of RNA structural motifs pose an attractive complementary target for small-molecule antiviral development, a strategy that has shown promise against a plethora of viruses $(13,14)$. Specifically, international efforts that allowed for identification and tracking of SARS-CoV-2 variants highlighted the large number of mutations accumulated in proteincoding regions (15). At the same time, recent global cataloging of mutations in the untranslated regions (UTRs) revealed a lower rate of mutation, highlighting the potential of UTRs as drug targets (16). Recently published data on genome-wide secondary structure of the virus obtained by in vitro and in vivo SHAPE (selective $2^{\prime}$ hydroxyl acylation analyzed by primer extension) and DMS (dimethyl sulfate) probing of SARS-CoV-2-infected Vero E6 cells, as well as nuclear magnetic resonance (NMR) characterization, recapitulates the computationally predicted stem loops (SLs) at the $5^{\prime}$-region of the genome (Fig. 2) as well other relevant frameshifting and replicationrelated structures $(17-20)$. Conserved elements at the $5^{\prime}$ - and $3^{\prime}$-ends have been identified across many members of the coronavirus family and function as cis-acting elements regulating viral replication (21). Specifically, studies on murine and bovine CoVs showed that phylogenetically conserved SLs in the $5^{\prime}$-UTR are capable of long-range RNA-RNA and protein-RNA interactions responsible for optimal viral replication $(22,23)$. More recently, studies aimed at uncovering 


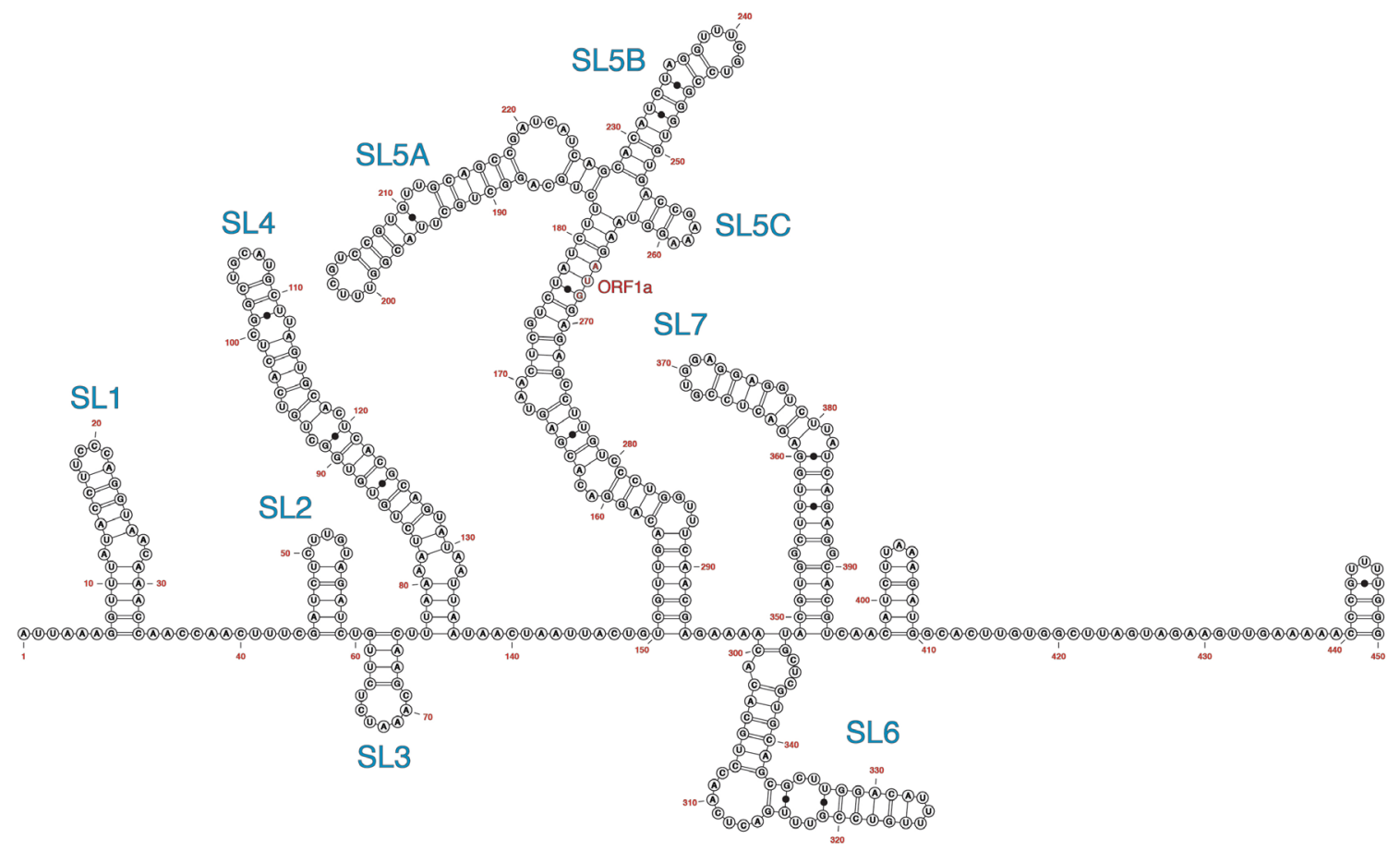

Fig. 2. Secondary structure representation of the 5 '-end ( $450 \mathrm{nt}$ ) of the SARS-CoV-2 RNA genome as determined by DMS chemical probing ( 18 ). Structure recreated in VARNA.

the pathway that leads to viral protein synthesis via host cell translation machinery revealed that the presence of the full-length $5^{\prime}$-UTR of SARS-CoV-2 leads to a fivefold increase in translation of viral proteins. This preliminary data corroborate the importance of the $5^{\prime}$-UTR region, and the structures within, for efficient viral translation and provide context for the viral hijacking of the host cell translational machinery (24).

Drug-like small molecules offer the ability to develop chemical probes that reveal function and to design bioavailable clinical candidates for treatment. While RNA targeting has lagged behind protein targeting, recent successes in both the laboratory and the clinic support its potential role. The first U.S. FDA-approved small molecule targeting RNA other than the ribosome was approved for treatment of spinal muscular atrophy in August of 2020 (25). Effective smallmolecule targeting in the laboratory has also been observed for a plethora of disease-relevant RNAs, including viral RNAs. Specifically, small molecules targeting structures within the $5^{\prime}$-UTR region have shown antiviral activity for a number of positive-sense RNA viruses such as HCV, FMDV, and EV71 (26-28). Recent studies have begun evaluating the potential of small molecules against the frameshifting elements of SARS-CoV-2 RNA in the coding region. These recent reports include evaluation of known SARS-CoV pseudoknot binders and development of a small-molecule binder to the attenuator hairpin preceding the pseudoknot (29-32). Coupling of the latter to the known ribonuclease-targeting chimera technology results in recruitment of cellular ribonucleases leading to viral genomic RNA degradation. In addition, a fragment-based screen against structures in the 5'-UTR of SARS-CoV-2 was successful in identifying potential ligands (31). While the antiviral activity of these molecules has not been published, these preliminary results, combined with known RNA-targeted antivirals for other positive-sense RNA viruses, stand as proof of concept of the targetability of SARS-CoV-2 RNA motifs.
Successful efforts to target viral $5^{\prime}$-UTR structures have often leveraged the synthetic tuning of a known RNA binding scaffold $(26,27,33)$. We recently used this approach to develop RNA-targeted antivirals based on dimethylamiloride (DMA) that target the internal ribosomal entry site (IRES) region in the $5^{\prime}$-UTR of EV71. The DMA scaffold had been previously reported to be poised for tuning for specific RNA constructs via a facile three-step synthesis (27). Further investigation and functionalization of the scaffold resulted in a bioactive antiviral analog that formed a repressive ternary complex with IRES SL II RNA and the human AUF1 protein, ultimately inhibiting translation and compromising viral replication. The successes in DMA exploration highlight the scaffold's potential for tuning and broad applicability as an antiviral scaffold (27).

Here, we report DMA analogs that show promising antiviral properties by reducing SARS-CoV-2 virus titer in a dose-dependent manner in infected cells. In addition, dual-luciferase reporter assays confirmed the antiviral activity of the small molecules to be dependent on the 5'-UTR and proximal region of the SARS-CoV-2 genome. Investigation of possible conserved RNA binding sites of the lead small molecules revealed putative bulge-like binding sites in SL1, SL4, and SL5a, located in the 5'-UTR of the SARS-CoV-2 genome, and in the adjacent SL6 located in ORF1a, supporting both the targetability of $5^{\prime}$-region SLs. Together, these results establish conserved CoV RNA structures as antiviral targets and reveal lead molecules with promising antiviral properties.

\section{RESULTS}

\section{Phylogenetic conservation of RNA structural elements}

As the functional significance of the $5^{\prime}$-end SLs is still being elucidated, we examined sequence conservation in the $5^{\prime}$-end region across the Betacoronavirus genus as a preliminary approach to assess the 
suitability of the known structures in this region as therapeutic targets. Sequence conservation within the contexts of folded RNA domains would imply selective pressures to exert biological function. We constructed a multiple sequence alignment spanning the $5^{\prime}$-UTR and the adjacent region including representatives of all five betacoronavirus subgenera (Fig. 3). Alignments disclosed the highest degree of conservation in the region encoding SL2 and SL3, both of which are relatively short and contain stretches of 5 to 6 nucleotides (nt) that are $100 \%$ conserved. By contrast, SL1 and SL4 to SL6 are less conserved, but notably, four of the five SLs that span the $5^{\prime}$-UTR contain stretches of relatively highly conserved nucleotide sequence (i.e., 70 to $100 \%$ conservation across the genus). The position of these SL's within or adjacent to the $5^{\prime}$-UTR (which is relatively conserved in length across all Betacoronaviruses) indicates that these conserved regions are likely to represent homologous nucleotides and suggests that they are, to some degree, functionally equivalent. Our findings are in agreement with recent studies that reported sequence and structural similarity among members of the Coronaviridae family, suggesting that selective pressure plays a central role in conserving RNA secondary structures essential for the viral life cycle.

\section{DMAs inhibit human coronavirus $0 C 43$ virus replication in a dose-dependent manner}

We pursued targeting of the $5^{\prime}$-end SL structures with the DMA scaffold, which has been previously reported as an RNA binding scaffold that can be successfully optimized for selectivity for distinct RNA elements (27). To quickly assess potential CoV antiviral activity, human OC43 betacoronavirus was used because of its lower virulence and thus suitability for use in standard cell culture facilities (3). Vero E6 cells were infected with human coronavirus OC43 at a multiplicity of infection $(\mathrm{MOI})=1$. After a 1-hour adsorption, a panel of 23 DMAs at 50 or $100 \mu \mathrm{M}$ were added to the cells and incubated for 24 hours at $33^{\circ} \mathrm{C}$. Virus titers were determined by plaque formation on Vero E6 cells, and DMA-132, DMA-135, and DMA-155 (Fig. 4) reduced virus titer by $\sim 1000$-fold at $100 \mu \mathrm{M}$ concentration (fig. S1). The results further suggest DMA-132, DMA-135, and DMA-155 reduce virus titer in a dose-dependent manner (fig. S2). The parent scaffold, DMA (DMA-1), demonstrated no activity and is used as an inactive control moving forward.

\section{Antiviral potency of DMAs against SARS-CoV-2}

To determine the antiviral activity and potency of the lead small molecules against SARS-CoV-2, we used a simplified quantitative reverse transcription polymerase chain reaction (qRT-PCR) assay to monitor SARS-CoV-2 viral RNA levels in supernatants of infected Vero E6 cells (34). Similarly to remdesivir, DMA-135 and DMA-155 led to a dose-dependent 10 - to 30 -fold decrease in cell-free viral RNA levels within 24 hours of infection with an approximate median inhibitory concentration ( $\mathrm{IC}_{50}$ ) of 10 and $16 \mu \mathrm{M}$, respectively (fig. S4).

Antiviral activity of the three most active DMA leads (DMA-132, DMA-135, and DMA-155) was confirmed using Vero E6 cells infected with wild-type SARS-CoV-2. Small-molecule treatment was performed at 10 and $50 \mu \mathrm{M}$, respectively. DMA-132 and DMA-135 showed dose-dependent reduction in virus titer compared to dimethyl sulfoxide (DMSO), as measured by median tissue culture infectious dose $\left(\mathrm{TCID}_{50}\right)$ assay, without measurable effect on cellular viability as measured by adenosine $5^{\prime}$-triphosphate (ATP) content (Fig. 5). Virus titer and cellular content of ATP (CellGro) were normalized to account for the expected variance of raw virus titer between experiments. Notably, all three DMA-132, DMA-135, and DMA-155 have improved antiviral activity when compared to DMA-01, the parent scaffold, thereby corroborating the potential for synthetic tunability of DMAs for SARS-CoV-2 targeting.

DMA-132, DMA-135, and DMA-155 were tested for longer-term (96-hour) toxicity in Vero E6 cells. Small molecules do not substantially reduce cell viability $<10 \mu \mathrm{M}$, supporting a potential therapeutic window, although more extensive cytotoxicity studies are warranted. In particular, fig. S3 shows that the $50 \%$ cytotoxic concentration $\mathrm{CC}_{50}$ of DMA-132 and DMA-135 in Vero E6 cells were $>100 \mu \mathrm{M}$. $\mathrm{CC}_{50}$ of DMA-155 was about $90 \mu \mathrm{M}$; so, only $10 \mu \mathrm{M}$ antiviral data were collected.

\section{Investigation of small-molecule activity against CoV-2-luciferase reporter gene expression}

To assess the effect of DMAs on reporter gene expression directed by SARS-CoV-2 sequence elements, a reporter plasmid, pCoV-2$5^{\prime} \mathrm{UTR}-\mathrm{FLuc}-3^{\prime} \mathrm{UTR}$ was used as template for in vitro synthesis of CoV-2-5'UTR-FLuc-3'UTR RNA (Fig. 6A). This plasmid contains the $5^{\prime}$-end 805-nt segment from the virus genome and the $3^{\prime}$-UTR. Thus, the 805-nt segment spans the genomic RNA 5'-UTR (SL1 to SL5) and ORF1a encoding a portion of nsp1 (including SL6 to SL8) fused in-frame with the firefly luciferase (FLuc) ORF. Plasmid pRL was used as template for the synthesis of control Renilla luciferase (RLuc) reporter RNA lacking SARS-Cov-2 sequences. The RNAs were cotransfected, and various concentrations of DMAs were added with the transfections. Two days after transfection, RLuc and FLuc activities were measured using a dual-luciferase reporter assay. As shown in Fig. 6A, addition of $10 \mu \mathrm{M}$ DMA-132 or DMA-135 reduced FLuc activity, which is under the control of SARS-CoV-2 $5^{\prime}$-end and $3^{\prime}$-UTR, by approximately $50 \%$. Addition of $10 \mu \mathrm{M}$ DMA-155 resulted in the largest decrease in FLuc activity; specifically, FLuc signal was reduced by $\sim 90 \%$. A similar level of FLuc signal reduction was achieved in the presence of 10-fold higher concentration of DMA-132 and DMA-135 when compared with DMA-155. Activities of the control RLuc remained relatively constant for all DMAs across all concentrations tested; this control indicates that decreases in FLuc required SARS-CoV-2 sequence elements and were not due to any putative cytotoxic effects of DMAs or to nonspecific effects on translation. To test whether the CoV-2 3'-UTR contributes to DMA-mediated translational repression, we repeated the experiment using a FLuc reporter, CoV-2-5'UTR-FLuc RNA, in which the CoV-2 $3^{\prime}$-UTR was replaced with vector-encoded sequence; thus, the $\mathrm{CoV}-25^{\prime}$-ends of both FLuc reporter RNAs are the same (Fig. 6B). The effects of DMAs on translational repression were virtually identical to those in Fig. 6A. We note that select DMAs that inhibited SARS-CoV-2 5'-end-dependent FLuc translation (this work) had little effect on EV71 5'-UTR-dependent FLuc translation (27). Thus, the DMAs act at the level of the SARS-CoV-2 5 '-end and not at the level of putative structure present in the FLuc coding region. Together, these results clearly demonstrate that DMA-dependent suppression of SARS-CoV-2 luciferase reporter activity requires only $5^{\prime}$-end sequences of the virus.

\section{NMR profiling and in vitro affinity of 5'-SL-DMA interactions}

Toward understanding potential mechanisms by which the DMAs inhibit SARS-CoV-2 replication, we carried out single-point ${ }^{13} \mathrm{C}-{ }^{1} \mathrm{H}$ TROSY HSQC (transverse relaxation-optimized spectroscopyheteronuclear single quantum coherence) titrations of DMA-132, 


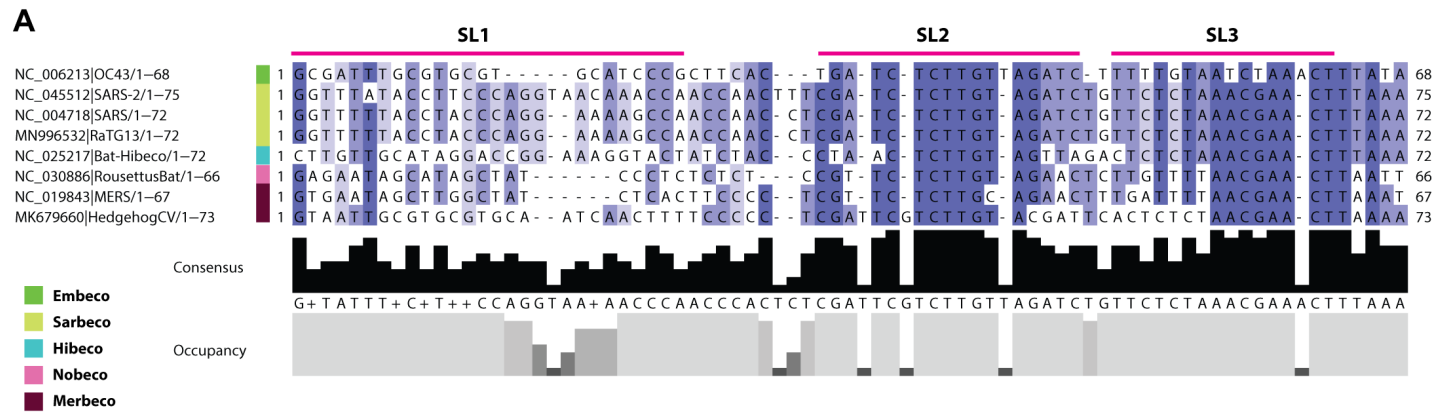

B
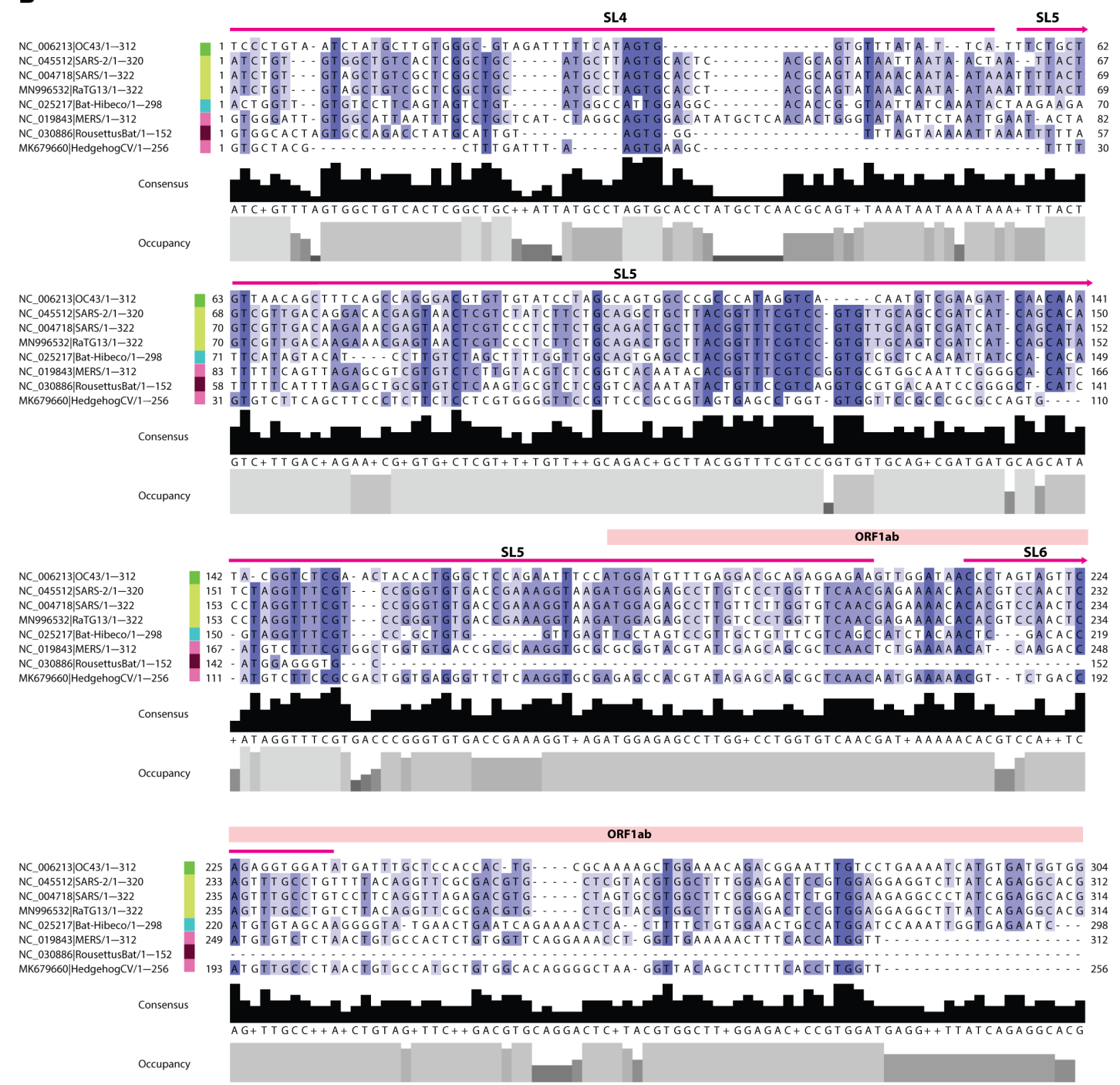

Fig. 3. Conservation of 5 '-end sequences encoding RNA structures in betacoronavirus genomes. Multiple sequence alignment showing percentage identity and sequence coverage within the 5'-UTR and adjacent region of representative species within genus Betacoronavirus. (A) SL1-3. (B) SL 4-6. Viral subgenus is indicated as shown in the key. Sequence numbering is standardized to the genome sequence start position of each taxon. Taxon labels show GenBank accession numbers and abbreviated virus names. OC43, human coronavirus OC43; RousettusBat, Rousettus bat coronavirus; MERS, Middle East respiratory syndrome-related coronavirus; Bat-Hibeco, Bat Hp-betacoronavirus.

DMA-135, and DMA-155 into SL1 to SL6 of the $5^{\prime}$-region. We selected this region of the $5^{\prime}$-UTR to NMR profile following the reasoning that it contains SLs with assigned functions that can be prepared at sizes amenable to facile NMR screening, shows a degree of selective pressure to maintain sequence and structure, and contains several noncanonical RNA elements that we hypothesize are good targets for the DMAs. An advantage of using ${ }^{13} \mathrm{C}-{ }^{1} \mathrm{H}$ TROSY HSQC titrations to profile small molecule-RNA interactions is 
<smiles>CN(C)c1nc(N)c(C(=O)NC(=N)N)nc1-c1ccccc1</smiles>

DMA-132<smiles>CN(C)c1nc(N)c(C(=O)NC(=N)N)nc1C#Cc1ccccc1</smiles>

DMA-135<smiles>CN(C)c1nc(N)c(C(=O)NC(=N)N)nc1-c1ccc(-c2ccccc2)cc1</smiles>

DMA-155

Fig. 4. Chemical structure of the three lead molecules derived from the focused library screen against OC43-infected Vero E6 cell screening.

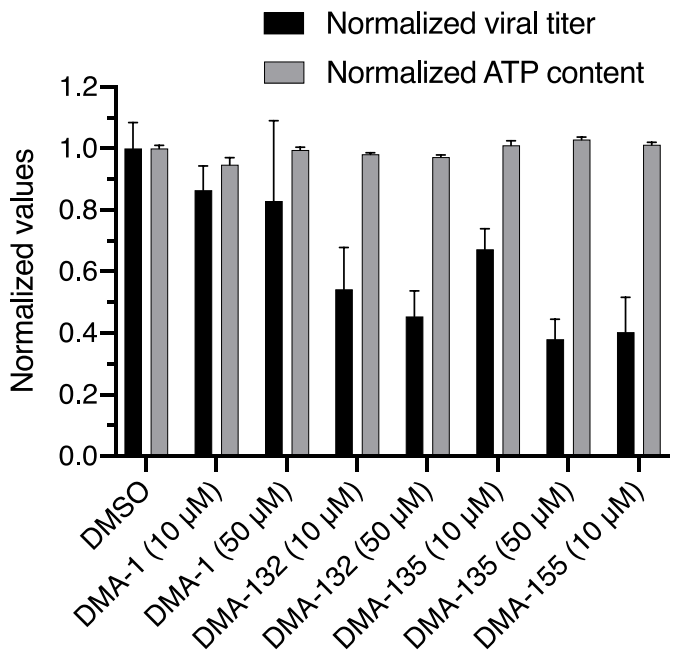

Fig. 5. Inhibition of SARS-CoV-2 infection by DMA leads without cellular toxicity. Vero E6 cells were infected with SARS-CoV-2 $(\mathrm{MOI}=0.1)$ in the presence of DMSO or the indicated compounds for 3 days followed by normalized measurement of virus titer in culture supernatant (black bars). Results were generated with two independent experiments, each with two replicates. Cellular viability was assayed by measuring cellular ATP content in uninfected Vero E6 cells after 3 days of treatment with the indicated compounds (gray bars).

that the extent of NMR signal perturbation provides a convenient proxy on the degree of binding specificity, even in the absence of chemical shift assignments. The designs of the individual SLs were based on the reasoning that DMAs likely bind the $5^{\prime}$-region SLs at noncanonical structural elements such as bulge, internal, or apical loops. Therefore, we in vitro transcribed isolated SL domains using ${ }^{13} \mathrm{C},{ }^{15} \mathrm{~N}$ rNTPs (ribonucleoside triphosphate) that would maximize NMR signal detection for the noncanonical elements over the base paired regions (Fig. 7 and fig. S5). For example, SL1 was prepared separately as $\mathrm{A}\left({ }^{13} \mathrm{C},{ }^{15} \mathrm{~N}\right)$ and $\mathrm{C}\left({ }^{13} \mathrm{C},{ }^{15} \mathrm{~N}\right)$ selectively labeled constructs because adenosines and cytosines are the most abundant nucleobases within or proximal to its internal and apical loops, respectively. Using this strategy, we are able to efficiently profile each $5^{\prime}$-region SL to determine whether the DMAs bind with reasonable affinity and specificity as determined by qualitative assessment of the DMA-induced NMR signal perturbation. Figure 7 and fig. S5 summarize the effects that the addition of excess (5:1) DMAs has on the NMR spectra of each major SL domain. First, we observed that the DMAs induced differential chemical shift perturbations (CSPs) or line broadening (LB) for each SL, and the largest signal perturbations (CSPs or LB) were observed in spectra recorded for SL1, SL4, SL5a, and SL6 (Fig. 7). The assignments of SL1 and SL5a have been
A

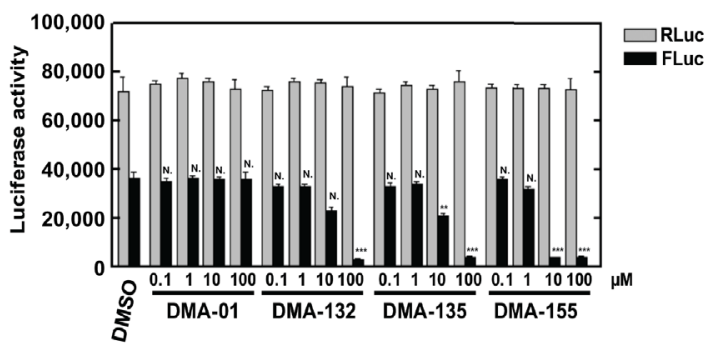

B

Fig. 6. Vero E6 cells were cotransfected with luciferase constructs and cultured with various concentration of small molecule. (A) Vero E6 cells were cotransfected with CoV-2-5'UTR-FLuc-3'UTR. (B) Vero E6 cells were cotransfected with Cov-2-5'UTR-FLuc (left), and no change in inhibition was observed when compared to the presence of 3'-UTR (right, DMA-135). Luciferase activity was measured 2 days later. Mean values and SDs from three independent experiments are shown in the bar graphs. ${ }^{* * *} P<0.001 ;{ }^{* *} P<0.01 ; N$., not significant relative to the DMSO control, except for the 5'UTR-FLuc-3'UTR comparison in (B), which is relative to DMA-135 at $0.1 \mu \mathrm{M}$.

previously reported $(35,36)$. Each of these $5^{\prime}$ domains contains bulges and/or other internal loops. Second, only a subset of the ${ }^{13} \mathrm{C}-{ }^{1} \mathrm{H}$ correlation peaks is perturbed in the spectra, providing initial evidence that the DMAs interact through specific surfaces rather than delocalized binding. Third, the extent of the signal perturbations is also differential between DMAs, with some DMAs inducing shifts of the correlation peaks to new positions within the spectra of a given SL and others inducing severe LB of the NMR signals. These variable signal perturbations suggest that the DMAs interact with different binding affinities and binding modes. None of the DMAs caused substantial changes to spectra recorded on SL2, which contains a 5-nt CUUGU apical loop but no internal loops or bulges. Together, the single-point ${ }^{13} \mathrm{C}-{ }^{1} \mathrm{H}$ TROSY HSQC titrations provide compelling evidence that the DMAs make specific interactions with the SARS-CoV-2 5'-region via surfaces composed of noncanonical structural elements. 


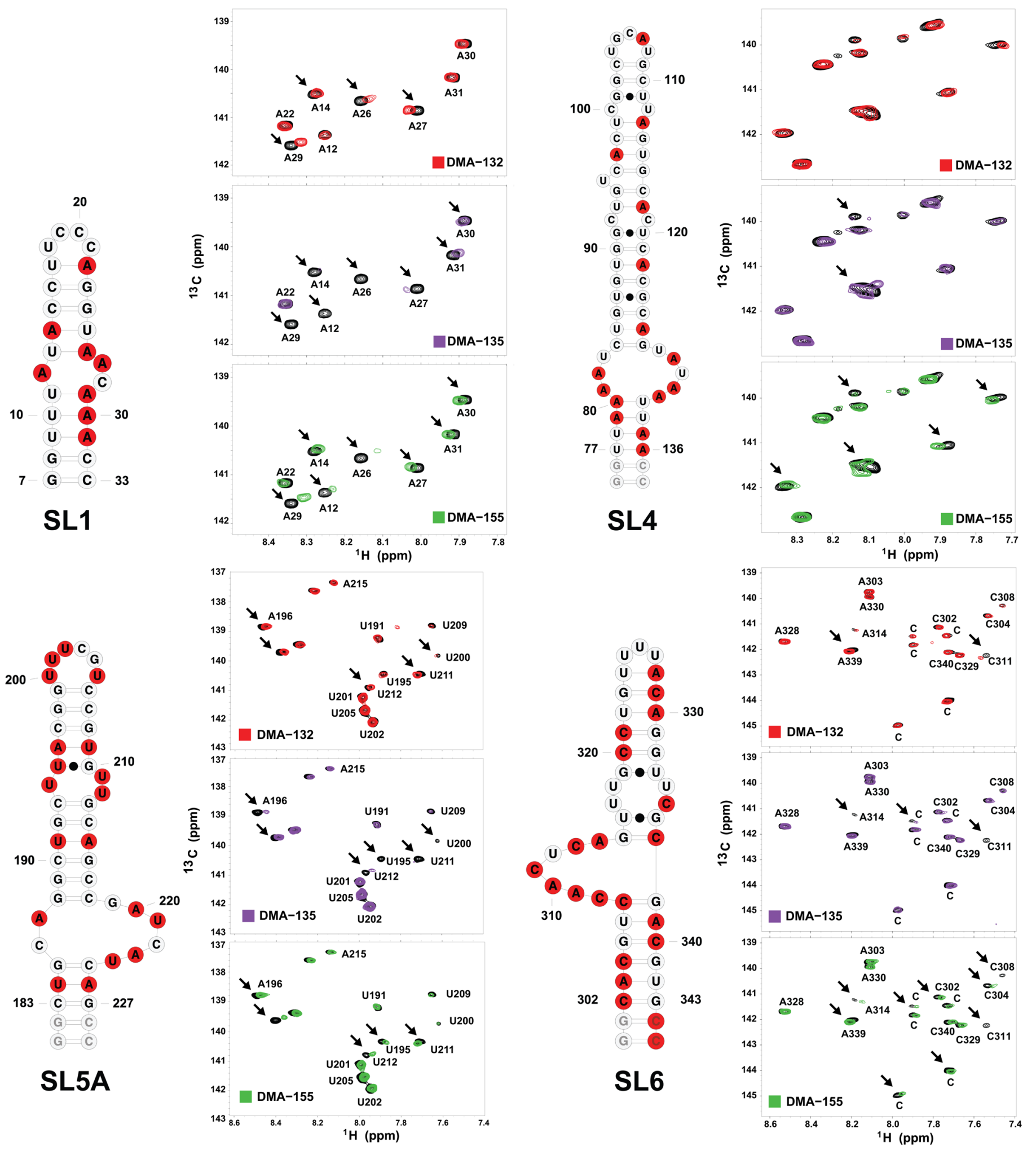

Fig. 7. Single-point ${ }^{13} \mathrm{C}-{ }^{1} \mathrm{H}$ TROSY HSQC titrations reveal that DMA-132, DMA-135, and DMA-155 bind with moderate affinity and specificity to SARS-CoV-2 5'-region SLs. The spectra were recorded at $900 \mathrm{MHz}$ in $100 \% \mathrm{D}_{2} \mathrm{O}$ buffer of $25 \mathrm{mM} \mathrm{K}_{2} \mathrm{HPO}_{4}$ and $50 \mathrm{mM} \mathrm{KCl}$ at pH 6.2. Temperatures (298, 303, or $308 \mathrm{~K}$ ) were optimized for each RNA construct to maximize the number of observed correlation peaks. The total RNA concentrations were set to $100 \mu \mathrm{M}$ while titrating fivefold excess DMA. 
Notably, SL1 and SL6 experienced the most substantial NMR signal perturbations upon addition of excess DMAs (Fig. 7). NMR signal perturbations are observed at other SLs but to a lesser degree based on our selection criteria. For SL1, addition of DMA-132 and DMA-155 induced the migration of several correlation peaks to new spectral positions (Fig. 7). By comparison, addition of DMA-135 induced severe $\mathrm{LB}$ of $\sim 50 \%$ of the total observed correlation peaks recorded for the $\mathrm{A}\left({ }^{13} \mathrm{C},{ }^{15} \mathrm{~N}\right)$ and $\mathrm{C}\left({ }^{13} \mathrm{C},{ }^{15} \mathrm{~N}\right)$ selectively labeled $\mathrm{SL} 1$ constructs (Fig. 7 and fig. S5). In the presence of fivefold excess DMA-135, most of the nuclear Overhauser effect (NOE) stacking patterns disappear for a $\mathrm{CG}\left({ }^{2} \mathrm{H}\right), \mathrm{AU}\left({ }^{2} \mathrm{H}_{3^{\prime}-5^{\prime \prime}}\right)$ selectively labeled SL1 construct, whereas substantially more NOE cross-peaks are still observed for the 5:1 (DMA-155)-SL1 complex (fig. S6). These differences likely reflect binding heterogeneity and collectively suggest that DMA-132, DMA-135, and DMA-155 differentially interact with SL1 despite having similar core scaffolds (Fig. 7).

For SL6, addition of excess DMA-155 induced a combination of CSPs and LB to a greater extent than DMA-132 or DMA-135. To further assess the nature of these signal perturbations on the SL6 structure, a ${ }^{1} \mathrm{H}-{ }^{1} \mathrm{H}$ NOE spectroscopy (NOESY; $t_{\mathrm{m}}=250 \mathrm{~ms}$ ) spectrum was recorded with $\mathrm{UG}\left({ }^{2} \mathrm{H}\right), \mathrm{AC}\left({ }^{2} \mathrm{H}_{3^{\prime}-5^{\prime \prime}}\right)$ selectively labeled SL6 constructs, which was chosen based on the abundance of $\mathrm{A}$ and $\mathrm{C}$ residues in the bulge (Fig. 8A). Figure 8 shows the ${ }^{1} \mathrm{H}-{ }^{1} \mathrm{H}$ NOESY spectra of free SL6 overlaid with its complex to which a 5:1 molar ratio of DMA-155 was added. On the basis of the intra-NOEs observed between A and C residues of SL6, tentative chemical shift assignments were determined (Fig. 8, B and C). The addition of excess small molecule caused CSPs to A339H8, A339H2, A310H8, $\mathrm{A} 310 \mathrm{H} 2, \mathrm{C} 311 \mathrm{H} 6$, and $\mathrm{A} 314 \mathrm{H} 8$ spin systems, which are located within or in proximity to the bulge. This supports a model in which DMA-155 preferentially interacts with the bulge region of SL6. Notably, the presence of intra-NOEs in the complex indicates the preservation of base stacking within the (DMA-155)-SL6 complex. In addition, the ${ }^{1} \mathrm{H}-{ }^{1} \mathrm{H}$ NOESY spectra of $\mathrm{CUG}\left({ }^{2} \mathrm{H}\right), \mathrm{A}\left({ }^{2} \mathrm{H}_{3^{\prime}}-5^{\prime \prime}\right)$ selectively labeled SL6 overlaid with its DMA-155-bound form (Fig. 8C) show inter-NOEs between the methyl protons of DMA-155 [2.5 parts per million (ppm)] and both A339H2 (7.94 ppm) and $\mathrm{A} 310 \mathrm{H} 2(7.88 \mathrm{ppm})$, although these particular inter-NOEs are weak. As further evidence of the involvement of A339 and A310 in binding, their H8 spin systems also showed CSPs upon the addition of DMA-155. Four additional broad NOE peaks appeared between the methyl protons and protons with chemical shifts between $\sim 6.5$ and 7 ppm (Fig. 8C). We reasoned that these might be intra-NOEs between the methyl groups and amino group located on the central six-membered ring system. To further investigate the origin of these NOEs, a ${ }^{1} \mathrm{H}-{ }^{1} \mathrm{H}$ NOESY spectrum of ACGU $\left({ }^{2} \mathrm{H}\right)$-labeled SL6 bound to DMA-155 (shown in orange, Fig. 8C) displayed identical broad NOE peaks. This shows that these peaks signify intra-NOEs within DMA-155 itself, which do not appear in the ${ }^{1} \mathrm{H}$ spectrum of the free small molecule in $\mathrm{D}_{2} \mathrm{O}$ but only in the environment of the SL6 complex. The possibility of these peaks arising from inter-NOEs between the amino of the RNA and methyl protons was eliminated on the basis of ${ }^{15} \mathrm{~N}$-HSQC NMR experiments of DMA-155 titrated into ${ }^{15} \mathrm{~N}$ fully labeled SL6. In sum, through the support of intra- and inter-NOEs, DMA-155 shows a degree of specificity to the bulge region of SL6.

Moreover, the affinity of the three leads for the SL constructs was investigated via in vitro indicator displacement assays (IDAs) $(27,37,38)$. DMA-155 was revealed to be a strong binder with the highest affinity for SL6, in agreement with NOE studies (Fig. 8 and fig. S17). DMA-135 showed weak affinity for SL1, SL4, and SL6; the parent scaffold (DMA-001) and DMA-132 did not show binding affinity against any of the constructs under these conditions. The measured $50 \%$ competitive displacement dose $\left(\mathrm{CD}_{50}\right)$ in vitro is about 10 -fold weaker than the $\mathrm{IC}_{50}$ recorded via luciferase assays, which may highlight the differences between these assays. $\mathrm{CD}_{50}$ measurements depend on both the affinity and binding mode of the indicator used, while in cell assays, these reflect binding in the presence of a larger RNA context and in the presence of proteins. Additional biophysical studies are underway to better understand the relationship between these in vitro and in cellulo assays.

\section{In silico ligand screening of DMA-focused library against 5'-UTR and adjacent RNA structures}

To generate potential three-dimensional (3D) models of each SL, we used fragment assembly of RNA with full-atom refinement (FARFAR). We chose FARFAR to generate preliminary models as it has consistently been demonstrated to be the most accurate RNA 3D prediction algorithm $(39,40)$. We generated between 5000 and 100,000 models for each SL and then generated $\sim 15$ representative clusters.

The lowest energy conformation from each cluster was used to generate an ensemble for each SL that was submitted to ICM pocket finder to find and characterize possible binding pockets (table S1). Notably, SL2, which showed no change in ${ }^{13} \mathrm{C}-{ }^{1} \mathrm{H}$ HSQC NMR chemical shifts upon small-molecule addition, did not have any identifiable binding pocket. SL1, SL3, and SL5b presented binding pockets with low to intermediate scores in terms of volume, area, hydrophobicity, buriedness, and druggability score (DLID) parameters often used to describe a binding pocket's fitness. Notably, SL3 and SL5b presented minor CSPs upon small-molecule addition. ${ }^{13} \mathrm{C}-{ }^{1} \mathrm{H}$ TROSY HSQC NMR experiments showed notable changes upon smallmolecule binding to SL1, SL5a, and SL6 (Fig. 7), all of which had the highest scores in all parameters (Fig. 9). The structure that presents the highest CSPs upon binding to the small-molecule leads, SL6, is the only SL to have a binding pocket with positive DLID score (0.45; table S1). DLID score has been found as a good predictor of druggability of protein binding pockets but often presents highly negative scores in RNA due to the charged backbone of RNA $(41,42)$. Overall, this binding pocket analysis strongly correlates with NMR experimental data.

We then docked our published 55-member DMA library against the clustered FARFAR-generated SL structures (figs. S7 to S12). In line with the results from the pocket analysis and NMR experimental data, the overall number of hits across constructs is highest for SL1, SL4, SL5a, and SL6, corroborating their potential as therapeutic targets. Hit ligands DMA-132, DMA-135, and DMA-155 were among the top predicted binding ligands. Furthermore, if the docked structures are limited to the sublibrary of DMAs tested against OC43 and SARS-CoV-2, the three hit ligands score in the top 5 of every SL. Notably, when analyzing the binding location that yielded the best docking scores of the three hit molecules against SL6, we note that while DMA-135 and DMA-155 bound best in one binding pocket (Fig. 9F, blue), DMA-132 docks best in the adjacent binding pocket (Fig. 9F, red). When comparing the NMR profiles of the three small molecules, we note that DMA-135 and DMA-155 have a similar perturbation pattern, while DMA-132 has a slightly different profile, suggesting a possible different binding mode. To further investigate this hypothesis, FARFAR 3D models were generated for every individual bulge and apical loop motif to increase the conformational 
A

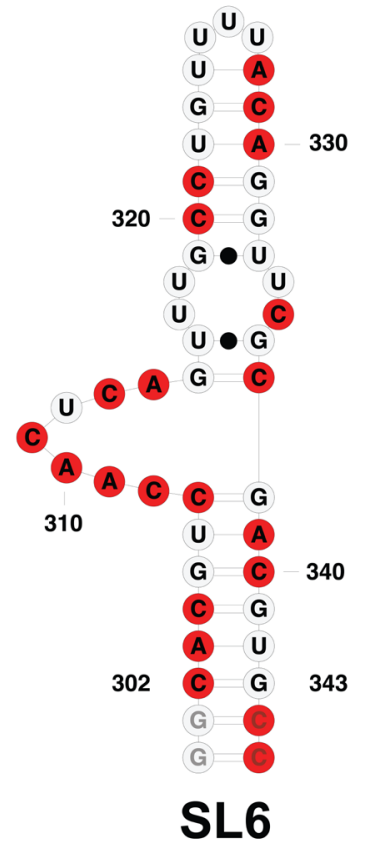

B

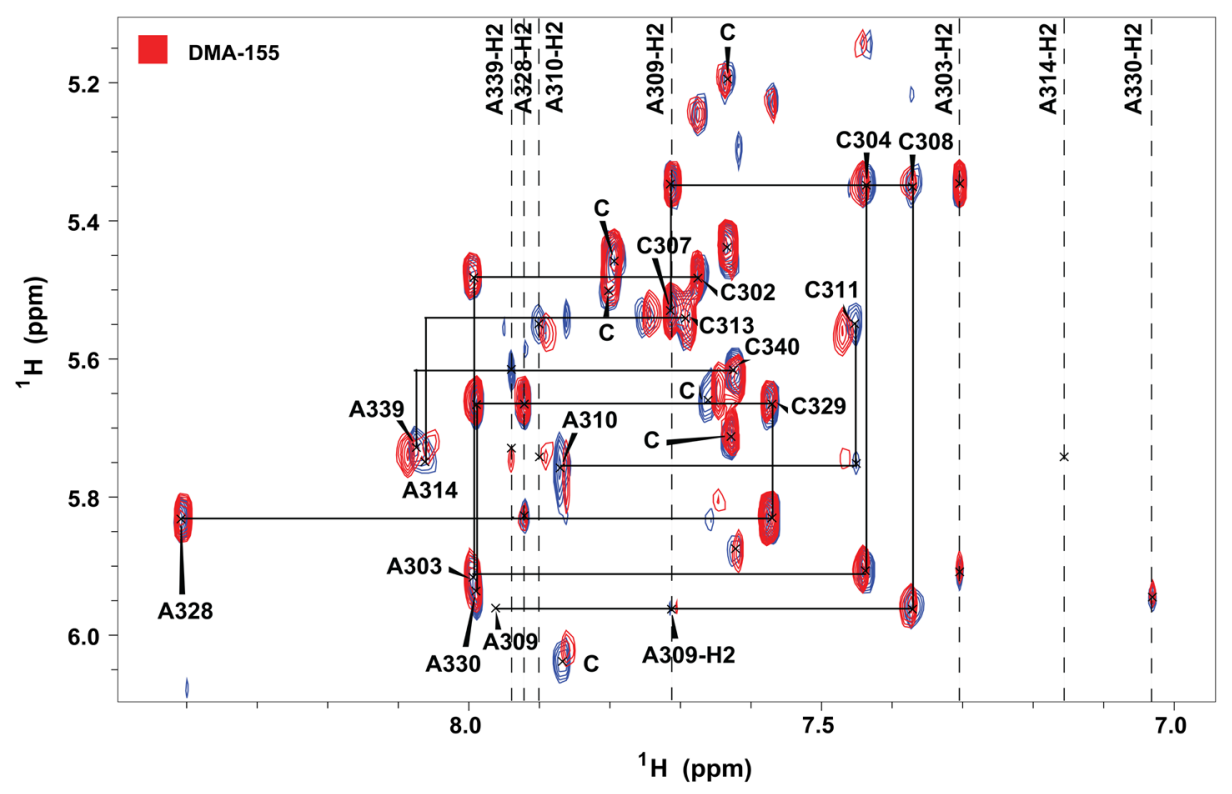

C

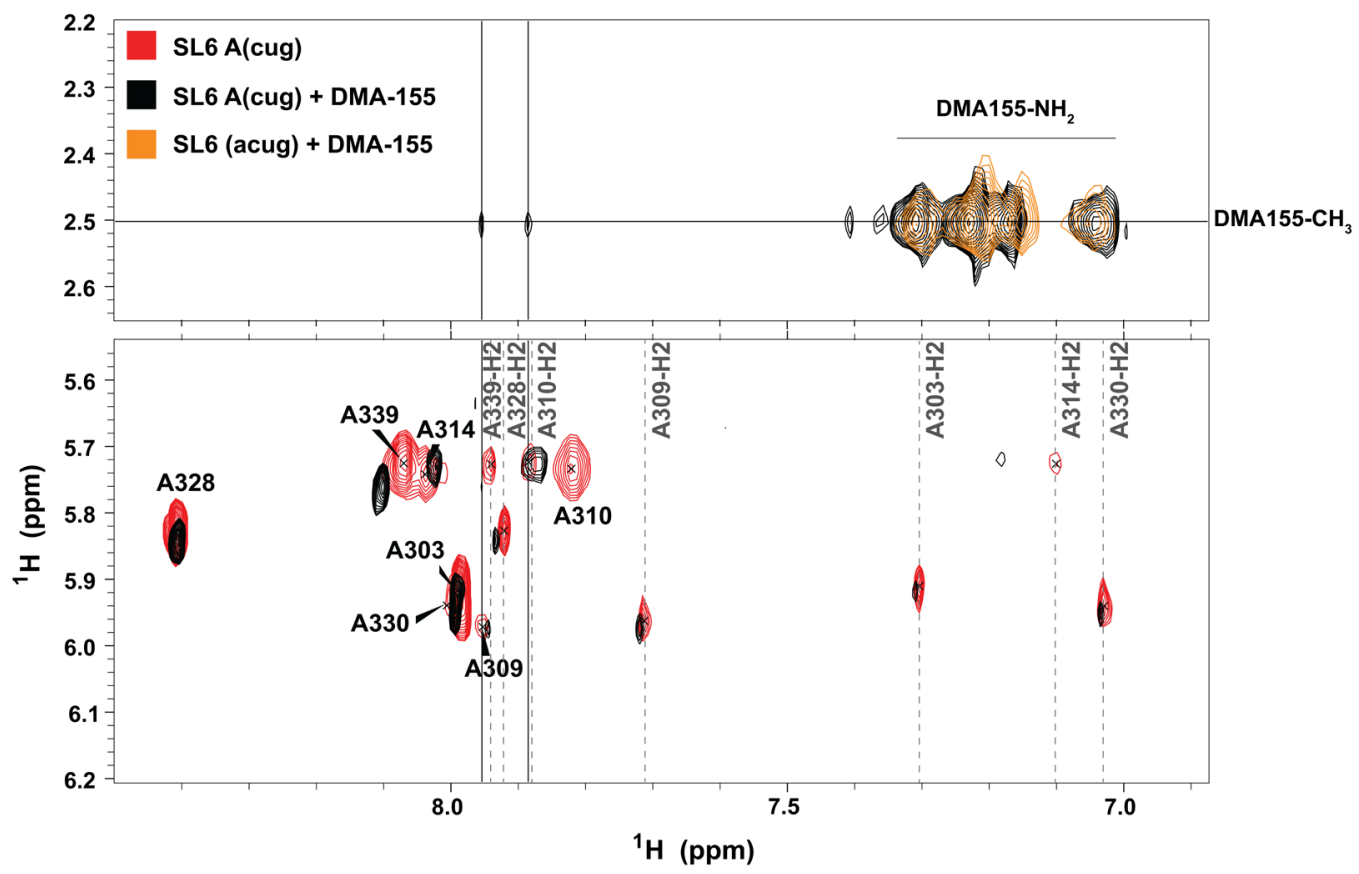

${ }^{1} \mathrm{H}(\mathrm{ppm})$

Fig. 8. Detailed interaction of DMA-155 with SL6. (A) Representation of SL6 secondary structure and labeled nucleotides (red). (B) ${ }^{1} \mathrm{H}-{ }^{1} \mathrm{H}$ NOESY spectra (900 MHz, $t_{\mathrm{m}}=250 \mathrm{~ms}$ ) of free $\mathrm{UG}\left({ }^{2} \mathrm{H}\right), \mathrm{AC}\left({ }^{2} \mathrm{H}_{\left.3^{\prime}-5^{\prime \prime}\right)}\right.$ selectively labeled SL6 (blue) and its DMA-155 complex (red), which were collected in $25 \mathrm{mM} \mathrm{K}_{2} \mathrm{HPO}$ and $50 \mathrm{mM} \mathrm{KCl}$ (pH 6.2$)$ at

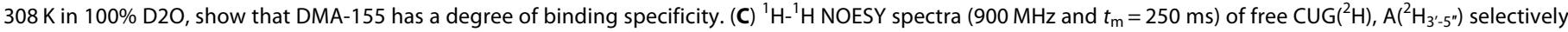
labeled SL6 (red), its DMA-155 complex (black), and the fully deuterated RNA complexed with DMA-155 (orange) were collected in $25 \mathrm{mM} \mathrm{K}_{2} \mathrm{HPO}_{4}$ and $50 \mathrm{mM} \mathrm{KCl}$ (pH 6.2 ) at $308 \mathrm{~K}$ in $100 \% \mathrm{D}_{2} \mathrm{O}$. On the secondary structure of $\mathrm{SL} 6$, the nucleotides highlighted in red represent the labeling scheme of the RNA.

diversity at these sites within the SL clusters, which are otherwise largely dictated by the respective positions of the double stranded regions. The DMA library was then rescreened against each of the clustered motifs. The three small-molecule leads DMA-132, DMA-135, and DMA-155 consistently scored among the top hits (figs. S8 to S12). Furthermore, each of the molecules reported the best docking score for SL1, SL5a, SL6, and, more specifically, for motifs created for internal bulge motifs (figs. S13 to S15). In the case of DMA-135, for example, the best docking score was found for the internal loop motif of SL1, in agreement with HSQC data that reported DMA-135 as the best binder for SL1 (fig. S16). Analogously, DMA-155 had the best docking score for the internal loop pocket of SL6, in line with NOE data that identified DMA-155 as the best and most specific binder for SL6 (fig. S17). While preliminary, this docking analysis corroborates the NMR data and the fitness of these ligands for SARS-CoV-2 5'-SL targeting while also supporting its utility as a tool in the identification of new SARS-CoV-2 RNAtargeting ligands. 
A

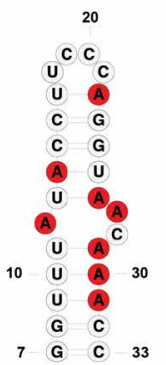

SL1

D

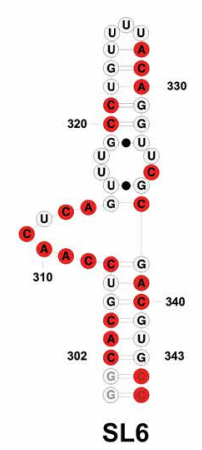

B

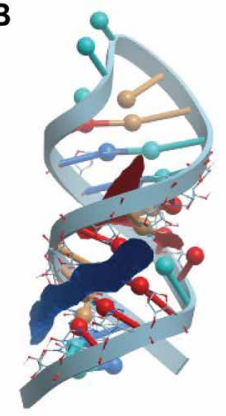

E

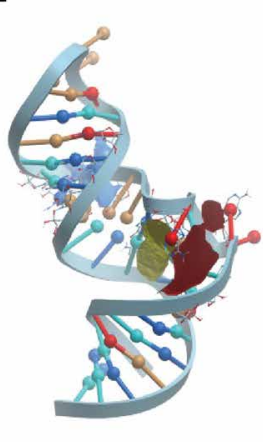

C

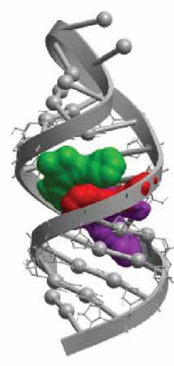

$\mathbf{F}$

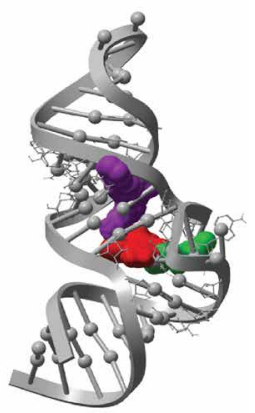

Fig. 9. Retrospective docking substantiates NMR findings. (A) Secondary structure representation of SL1 construct used in NMR studies. (B) SL1 3D model with binding pockets highlighted in different colors identified via ICM pocket finder. The model depicted is a representative conformer of the 15-confomer cluster generated for the internal loop motif. (C) conformation and binding pockets that yielded the best docking scores of the three hit molecules DMA-132 (red), DMA-135 (green), and DMA-155 (purple). (D) Secondary structure representation of SL6 construct used in NMR studies. (E) SL6 3D model with binding pockets (red and blue) identified via ICM pocket finder. Model depicted is a representative conformer of the 15-structure clusters built for internal loop motif. (F) Conformer that yielded the best docking scores for the three hit molecules, namely, DMA-132 (red), DMA-135 (green), and DMA-155 (purple) represented in space-filling model.

\section{DISCUSSION}

Screening of synthetic RNA-focused libraries in recent years has provided the field with many RNA binding bioactive small molecules and some of the highest hit rates among small-molecule screening approaches (43). Amiloride, a known RNA binding scaffold, has been synthetically tuned for a range of RNA secondary structures and recently yielded a novel antiviral lead for the treatment of enterovirus 71. In this case, amiloride inhibited viral translation by binding the viral 5'-UTR and modulating RNA:host protein interactions. SARS-CoV-2 also contains a highly conserved $5^{\prime}$-end that is reported to play a crucial role in viral replication and hijacking of host cell translational machinery. The presence of multiple bulge or internal loops, the secondary structural elements that amilorides have been reported to bind most effectively, makes the $5^{\prime}$-UTR and the adjacent SL6 ideal therapeutically relevant targets for small-molecule probing. An initial DMA-focused library screen against OC43infected Vero E6 cells allowed for the identification of three lead compounds, namely, DMA-132, DMA-135, and DMA-155, that significantly reduced virus titer. Initial structure-activity relationships could also be resolved, highlighting the critical substitution of the dimethylamine group at the C5 position and rigid aromatic

substituents at the C6 position. These molecules were also found to be active against SARS-CoV-2 in both screening-format qRT-PCR and infectious virus titer assays. Luciferase assays revealed the presence of the $5^{\prime}$-UTR and proximal region as necessary and sufficient for translation inhibition upon small-molecule treatment. Markedly, all in vitro assays identified DMA-155 as the strongest SARS-CoV-2 inhibitor, with the largest reduction in luciferase signal and highest decrease in virus titer at $10 \mu \mathrm{M}$.

NMR profiling of leads DMA-132, DMA-135, and DMA-155 against each of the major 5'-UTR and adjacent SL domains revealed that the DMAs bind preferentially to SLs that contain large internal or bulge loops. SL1's NMR data revealed CSPs and LB with DMA-135, which signifies its binding onto a specific surface with a disruption in stacking interactions, unlike DMA-155. Notably, SL6, which contains a moderately conserved and weakly paired $\sim 16$-nt bulge loop, showed one of the most notable CSPs when titrated with DMAs. Specifically, NOE experiments revealed that DMA-155 binds specifically to SL6, a finding that was corroborated by in vitro IDAs, which identified SL6 as the preferred target for DMA-155. The 5 -side of the SL6 bulge loop has been proposed to interact with the SARS-CoV-2 nucleocapsid $(\mathrm{N})$ protein under phase separation conditions and may also affect genome packaging (44). We will investigate the modulation of the $\mathrm{N}$ protein:SL6 interaction as a potential antiviral mechanism in future work.

In silico analysis corroborated the experimental trend observed with NMR experiments, identifying some of the SLs with predicted bulges (SL1, SL4, SL5a, and SL6) as those with binding pockets with highest druggability. The small molecules that showed the highest antiviral activity, namely, DMA-132, DMA-135, and DMA-155, scored highest in the SLs that reported substantial CSPs upon smallmolecule binding. In addition, refined docking of the three smallmolecule leads against motif-specific clusters revealed SL1 to be the preferred target for DMA-135 and SL6 as the favored target for DMA-155, in line with NMR and IDA results.

In summary, we here identified drug-like small molecules that reduce SARS-CoV-2 replication and are the first antivirals to target the conserved RNA SLs in the $5^{\prime}$-end region of SARS-CoV-2. Work is underway to further characterize the mode of action of these ligands, particularly putative impacts on RNA:protein interactions and specific steps in the viral replication cycle. These leads are uniquely poised to further elucidate the relationship between in vitro preferential binding and small molecule-mediated SL-specific alterations of virus:host interactions. These small molecules offer the opportunity to understand the contribution of individual $5^{\prime}$-end SLs to viral proliferation in a system where mutational studies are difficult because of genome size. Once characterized, we expect these amiloride-based ligands to serve as chemical biology tools to help understand CoV RNA molecular biology, such as N-dependent genome packaging and other cellular stages of the viral RNA replication process. We have established an efficient framework to identify novel RNA-targeted $\mathrm{CoV}$ antivirals that will serve not only the SARS-CoV-2 pandemic but future coronavirus pandemics.

\section{MATERIALS AND METHODS \\ Analysis of sequence conservation}

Representative betacoronavirus sequences were selected according to official taxonomy as represented by the International Committee for the Taxonomy of Viruses (45). Multiple sequence alignments of 
coronavirus sequences were constructed using BLAST and MAAFT as implemented in GLUE (46-48). Alignments were manually inspected and adjusted using Se-Al. Position coverage and percentage identity were calculated and visualized using JalView (49).

\section{Cells and virus}

Vero E6 (African green monkey kidney; ATCC CRL-1586) cells were cultured in minimum essential medium (MEM) supplemented with $10 \%$ fetal bovine serum (FBS) (Thermo Fisher Scientific) and maintained at $33^{\circ} \mathrm{C}$. Cells were infected with human coronavirus $\mathrm{OC} 43$ (ATCC VR-1558) at indicated MOI and incubated 1 hour at $33^{\circ} \mathrm{C}$ for adsorption. Unbound virus was removed, and cells were refed fresh medium with various concentrations of DMAs. Media from infected cells were harvested 24 hours postinfection, and virus titers were determined by plaque assay on Vero E6 cells. SARS-CoV-2 (USA-WA1/2020 strain; BEI Resources) was propagated and titered on Vero E6 cells, with sequence confirmation of a P2 stock to confirm stability of the viral genome.

\section{Effects of SARS-CoV-2 5'- and 3'-end sequence elements on luciferase reporter activity}

The reporter plasmid pCoV-2-5'UTR-FLuc-3'UTR contains the SARS-CoV-2 5'-UTR and adjacent coding sequences in ORF1a fused in-frame with the FLuc open reading frame, followed by the SARS-CoV-2 3'UTR. For plasmid pCoV-2-5'UTR-FLuc, the Cov$23^{\prime}$ UTR was replaced with vector-encoded sequence. The plasmids were provided by S.-R. Shih (Chang-Gung University, Taiwan). Plasmid pRL, the Renilla luciferase control reporter vector, was purchased from Promega. CoV-2-5'UTR-FLuc-3'UTR, Cov-2-5'UTRFLuc, and RLuc RNAs were in vitro synthesized from these plasmid templates using the MEGAscript T7 Transcription Kit (Thermo Fisher Scientific).

Vero E6 cells were seeded in 24-well plates. Two hundred nanograms of reporter RNA, $5 \mu$ l of SuperFect (Qiagen), and $400 \mu$ l of MEM with $10 \%$ FBS were combined and added to one well of cells. Cells were incubated at $33^{\circ} \mathrm{C}$ for 4 hours, media were changed, and various concentrations of DMAs were added. Two days after transfection, IRES activity was determined by measuring RLuc and FLuc activities using the Dual-Luciferase Reporter Assay System (Promega).

\section{Cytotoxicity assays}

Various concentrations of DMAs were added to Vero E6 cells in culture. The cells were incubated at $33^{\circ} \mathrm{C}$ for 96 hours. Cell viability was determined by MTT assay and measured at $570 \mathrm{~nm}$ according to the manufacturer's instructions (EMD Millipore). All experiments were performed in triplicate. The concentration of DMAs required to reduce cell viability to $50 \%$ of the control cells was expressed as $\mathrm{CC}_{50}$.

\section{SARS-CoV-2 antiviral assays}

Analysis of SARS-CoV-2 growth in cell culture supernatants was performed using a simplified qRT-PCR assay as explained before (34). Briefly, Vero E6 cells were infected with SARS-CoV-2 at an MOI of $0.1 \mathrm{IU}$ per cell in 96-well plates, and virus inoculum was removed 1 hour postadsorption and replaced with media containing serial dilutions of the DMA compounds. Five microliters of cell culture media containing released virions was collected at 24 hours post infection and processed as detailed in previous studies (34). Viral RNA levels were quantitated by qRT-PCR using primers specific to SARS-CoV-2 N gene and a standard curve derived from in vitro synthesized RNA encoding $\mathrm{N}$.

In addition, antiviral activity was tested against SARS-CoV-2 using a TCID 50 assay, and Vero E6 cells were seeded at $1 \times 10^{5}$ per well in a 24 -well plate at $37^{\circ} \mathrm{C}$ for 24 hours. Cells and samples were then transferred to a Biosafety Level 3 facility. Stocks of SARS-CoV-2 were diluted in Dulbecco's modified Eagle's medium (DMEM)/2\% FBS for a solution of 20,000 plaque-forming units ( $\mathrm{pfu}) / \mathrm{ml}$. Growth media was aspirated from 24 -well plates and replaced with $495 \mu \mathrm{l}$ of $\mathrm{DMEM} / 2 \%$ FBS containing SARS-CoV-2 $(20,000 \mathrm{pfu} / \mathrm{ml})$ for an MOI of 0.1. Five microliters of DMSO or compound was then immediately diluted into each well for final concentrations of 50 and $10 \mu \mathrm{M}$. Plates were incubated at $37^{\circ} \mathrm{C}$ for 72 hours. Media were then harvested, centrifuged at room temperature for 10 minutes at $1500 \mathrm{~g}$, and then used for TCID $_{50}$ assay. Serial dilutions of supernatant from the treated cells were added to Vero E6 cells in 96-well plates, and cells were monitored for cytopathic effect. Virus titer was calculated from the numbers of positive wells using a modified Reed and Muench method.

\section{Synthesis and purification of RNA SL constructs present at 5 '-end}

SL1 to SL6 of the $5^{\prime}$-end were in vitro transcribed using a standard protocol from synthetic DNA templates from Integrated DNA Technologies (Coralville, IA) $(50,51)$. The 3 - to $6-\mathrm{ml}$ reactions involved the use of purified recombinant T7 RNA polymerase expressed in BL21 (DE3) cells. Depending on the labeling scheme of each RNA, double-labeled, ${ }^{13} \mathrm{C}$ and ${ }^{15} \mathrm{~N}$, rNTPs and unlabeled rNTPs were used in the reaction. Nucleotide labeling of the SLs was based on the abundance of nucleotides in bulges and loops. The labeling pattern for the ${ }^{1} \mathrm{H}_{-}{ }^{13} \mathrm{C}$ HSQC experiments was as follows: SL1 C $\left({ }^{13} \mathrm{C},{ }^{15} \mathrm{~N}\right)$-labeled and $\mathrm{A}\left({ }^{13} \mathrm{C},{ }^{15} \mathrm{~N}\right)$-labeled, SL2 $\mathrm{U}\left({ }^{13} \mathrm{C},{ }^{15} \mathrm{~N}\right)$ labeled, SL3 AU $\left({ }^{13} \mathrm{C},{ }^{15} \mathrm{~N}\right)$-labeled, SL4 A $\left({ }^{13} \mathrm{C},{ }^{15} \mathrm{~N}\right)$-labeled, SL5a $\mathrm{AU}\left({ }^{13} \mathrm{C},{ }^{15} \mathrm{~N}\right)$-labeled, SL5b AU $\left({ }^{13} \mathrm{C},{ }^{15} \mathrm{~N}\right)$-labeled, and SL6 $\mathrm{AC}\left({ }^{13} \mathrm{C},{ }^{15} \mathrm{~N}\right)$ labeled. For the ${ }^{1} \mathrm{H}-{ }^{1} \mathrm{H}$ NOESY experiments, the labeling scheme was SL6 UG $\left({ }^{2} \mathrm{H}\right) \mathrm{AC}\left({ }^{2} \mathrm{H}_{3^{\prime}-5^{\prime \prime}}\right), \mathrm{CUG}\left({ }^{2} \mathrm{H}\right) \mathrm{A}\left({ }^{2} \mathrm{H}_{3^{\prime}-5^{\prime \prime}}\right)$, and $\mathrm{ACUG}\left({ }^{2} \mathrm{H}\right)$ selectively labeled constructs, along with a $\mathrm{CG}\left({ }^{2} \mathrm{H}\right), \mathrm{AU}\left({ }^{2} \mathrm{H}_{3^{\prime}-5^{\prime \prime}}\right)$ selectively labeled SL1 construct.

Next, the SLs were purified on denaturing gels, ranging from 8 to $16 \%$, and extracted using electroelution. After desalting with a Millipore Amicon Ultra- 4 centrifugal filter, the RNAs were annealed by heating for $2 \mathrm{~min}$ at $95^{\circ} \mathrm{C}$ and flash cooled on ice. The samples were thoroughly washed and concentrated down with a $100 \% \mathrm{D}_{2} \mathrm{O}$ buffer of $25 \mathrm{mM} \mathrm{K}_{2} \mathrm{HPO}_{4}$ and $50 \mathrm{mM} \mathrm{KCl}$ at $\mathrm{pH}$ 6.2. Using the NanoDrop 2000 software (Thermo Fisher Scientific), the theoretical extinction coefficients of the SLs were calculated to determine RNA concentrations. Samples for NMR titrations contained $100 \mu$ M RNA in $\mathrm{D}_{2} \mathrm{O}$ buffer with a final volume of $200 \mu \mathrm{l}$.

\section{NMR profiling of DMA interactions with 5'-end structures}

A $900-\mathrm{MHz}$ spectrometer was used to record all NMR data. The ${ }^{1} \mathrm{H}_{-}{ }^{13} \mathrm{C}$ HSQC titrations were recorded with $100 \mu \mathrm{M}$ of selectively labeled SL1 to SL6 in a $100 \% \mathrm{D}_{2} \mathrm{O}$ buffer of $25 \mathrm{mM} \mathrm{K}_{2} \mathrm{HPO}_{4}$ and $50 \mathrm{mM} \mathrm{KCl}$ at $\mathrm{pH} 6.2$ with a $200-\mu \mathrm{l}$ sample volume. Titrations of the DMA molecules into the different SLs were collected at a molar ratio of 5:1, DMA to RNA, at a temperature of either 298 , or 303 , or $308 \mathrm{~K}$. For each construct, temperature optimization experiments were done to determine the optimum temperature to conduct the titrations with. Also, based on the optimized temperatures, ${ }^{1} \mathrm{H}-{ }^{1} \mathrm{H}$ 
NOESY spectra $\left(t_{\mathrm{m}}=250 \mathrm{~ms}\right)$ of selectively labeled SL6 samples and their DMA-155 complexes were collected with a $200 \mu \mathrm{M}$ sample concentration in $25 \mathrm{mM} \mathrm{K}_{2} \mathrm{HPO}_{4}, 50 \mathrm{mM} \mathrm{KCl}$ (pH 6.2) in $100 \% \mathrm{D}_{2} \mathrm{O}$ at a 200- $\mu$ l sample volume. At similar conditions, ${ }^{1} \mathrm{H}-{ }^{1} \mathrm{H}$ NOESY spectra $\left(t_{\mathrm{m}}=250 \mathrm{~ms}\right)$ of selectively labeled SL1 were collected in the absence and presence of DMA-135 and DMA-155 at a 5:1 molar ratio. The NMR spectra were processed using NMRPipe/NMRDraw and analyzed with NMRView J or Sparky (52-54).

\section{Virtual ligand screening against SARS-CoV-2 5'-end RNA structures \\ FARFAR model generation}

FARFAR is part of the Rosetta 3 software package and can be obtained for free academic usage (https://www.rosettacommons.org/ software/license-and-download). Each SL was generated through the following protocol.

rna_helix.py is a python wrapper for the Rosetta executable $r n a_{-}$ helix.rna_helix.py and is available in \$ROSETTA/tools/rna_tools/bin, where \$ROSETTA is the Rosetta installation path. Below are the commands to generate SL1.

rna_helix.py -seq gguu aacc -resnum 1-4 24-27 -o helix_1.pdb rna_helix.py -seq acc ggu -resnum 8-10 17-19 -o helix_2.pdb

For each helix in an SL other than the nucleotides that flank bulges and loops, we prebuild as idealized A-form helices with the above commands. Modeling helical residues as idealized A-form substantially reduce computational time, allowing for more models to be built.

FARFAR modeling is performed through the rna_denovo executable rna_denovo-nstruct 1000 -s helix_1.pdb helix_2.pdb-fasta input. fasta-secstruct_file input.secstruct-minimize_rna true -out:file:silent farfar.out

where -nstruct is the maximum number of models requested, -fasta is the path of a fasta file containing the RNA sequence, -secstruct is the path of a file (input.secstruct) containing the RNA secondary structure in dot-bracket notation, -minimize_rna true minimizes the RNA after fragment assembly, $-s$ specifies the path to the pdb files that contain static structures of our helices, and -out:file:silent specifies the output file path to store all generated models. Each SL was run on 100 cores for 24 hours; the number of generated models is reported in table FARFAR (table S1).

To reduce the number of models to dock against, we performed fixed-width clustering using the rna_cluster executable

rna_cluster -in:file:silent farfar.out -nstruct 15 -cluster:radius RADIUS where -in:file:silent is a silent file of all models for a given $\mathrm{SL}$, -nstruct is the maximum number of clusters requested, and-cluster:radius is max distance in heavy-atom root mean square deviation between members of the same cluster.

\section{Small-molecule docking}

Virtual docking simulations were performed using ICM (55) (Molsoft LLC. La Jolla, CA) using the SARS-CoV-2 5'-UTR structures obtained from FARFAR modeling and clustering. RNA structural elements' binding pockets were defined using ICM Pocket Finder module, and all the small-molecule protonation states were adjusted to $\mathrm{pH} 7.0$ using ChemAxon (www.chemaxon.com). RNA ensembles were then combined into conformational stacks using ICM's "impose conformations." Then, to create "flexible receptors" to dock against that would reflect all of the conformations of each structure, ICM's "create 4D grid" function was used for each docking project. Each of the structures was then docked against a library of 55 DMA molecules. The DMA library was saved in .sdf file format, which was indexed for virtual ligand screening using ICM-Pro. The virtual screening simulation was implemented with a conformational search and optimization with a limit of 10 conformers per molecule. The thoroughness was left at level 10.

\section{Indicator displacement assay}

A serial dilution of the seven SL RNAs (SL1, SL2, SL3, SL4, SL5a, SL5b, and SL6) was performed in tris buffer $(50 \mathrm{mM}$ tris- $\mathrm{HCl}$ and $50 \mathrm{mM} \mathrm{KCl}$, at $\mathrm{pH} 7.4$ ) in a 96-well plate in triplicate. Eight microliters of each dilution was transferred to a 384-well plate followed by $8 \mu \mathrm{l}$ of a $500 \mathrm{nM}$ solution of RiboGreen dye in the same buffer (Invitrogen). The plates were excited at $487 \mathrm{~nm}$ (8-nm slit), and emission was recorded at $525 \mathrm{~nm}$ ( $8 \mathrm{~nm}$ slit; focal height, $11.3 \mathrm{~mm}$ ) using a CLARIOstar plate reader (BMG labtech). The affinity of the dye for the RNA construct was determined by fitting the raw fluorescence in GraphPad Prism version 8.3.1 for Macintosh [GraphPad Software, La Jolla, California, USA (www.graphpad.com)] by fitting to the [Agonist] versus response - variable slope model that uses Eq. 1

$$
Y=\text { Bottom }+\left(X^{\text {Hillslope }}\right) * \frac{\text { Top }- \text { Bottom }}{X^{\text {HillSlope }}+\mathrm{EC}_{50} \wedge \text { HillSlope }}
$$

where $Y$ is normalized percent change in fluorescence intensity, $X$ is RNA concentration, Bottom is lowest fluorescence percent change, and Top is highest fluorescence percent change. Affinity of the dye for the RNA construct was used as the ideal RNA concentration for small-molecule titrations.

The two most promising small-molecule leads (DMA-135 and DMA-155) were then screened against SL1, SL4, SL5a, SL5b, and SL6, but not against the short SL2 and SL3 for which the RiboGreen dye showed weak affinity.

A serial dilution of DMA-135 and DMA-155 (0, 0.5, 1.0, 2.5, 5, $10.0,12.5,15,20,25,40,50,75,100,225,400$, and $450 \mu \mathrm{M})$ was performed in phosphate buffer tris buffer $(50 \mathrm{mM}$ tris- $\mathrm{HCl}$ and $50 \mathrm{mM} \mathrm{KCl}$, at pH 7.4) in a 96-well plate in triplicate. Eight microliters of each dilution was transferred to a 384-well plate, followed by $8 \mu \mathrm{l}$ of a solution of SL RNA and $0.5 \mu \mathrm{M}$ RiboGreen (Invitrogen). The 384-well plates were at $4000 \mathrm{rpm}$ for $1 \mathrm{~min}$ and incubated in the dark for $30 \mathrm{~min}$. The plates were excited at $487 \mathrm{~nm}$ (8-nm slit), and emission was read at $525 \mathrm{~nm}$ (8-nm slit; focal height, $11.3 \mathrm{~nm})$ using a CLARIOstar plate reader (BMG Labtech). Percent fluorescence indicator displacement (\%FID) was calculated by subtracting and, subsequently, dividing by the blank wells with RNA-dye complex and no small molecule as shown in Eq. 2

$$
\% \mathrm{FID}=\left(\frac{F_{0}-F}{F_{0}}\right) * 100
$$

where $F_{0}$ is the fluorescence of the blank well with RNA + dye and no small molecule, and $F$ is the fluorescence of the well with all three components (RNA + dye + small molecule).

Each technical triplicate was averaged, and the resulting FID values were averaged between three independent experiments. The binding curve and median effective concentration $\left(\mathrm{EC}_{50}\right)$ value were obtained by using a nonlinear fit curve agonist versus response with variable slope at four parameters [GraphPad Prism Software version for Macintosh 8.3.1, La Jolla, California, USA (www.graphpadprism.com)] 
as shown in Eq. 1. Reported values are averages of three independent experiments $\pm \mathrm{SD}$.

\section{SUPPLEMENTARY MATERIALS}

Supplementary material for this article is available at https://science.org/doi/10.1126/ sciadv.abl6096

View/request a protocol for this paper from Bio-protocol.

\section{REFERENCES AND NOTES}

1. D. He, S. Zhao, Y. Li, P. Cao, D. Gao, Y. Lou, L. Yang, Comparing COVID-19 and the 1918-19 influenza pandemics in the United Kingdom. Int. J. Infect. Dis. 98, 67-70 (2020).

2. W. H. Organization, WHO Coronavirus Disease (COVID-19) Dashboard. (2021).

3. B. Chen, E. K. Tian, B. He, L. Tian, R. Han, S. Wang, Q. Xiang, S. Zhang, T. el Arnaout, W. Cheng, Overview of lethal human coronaviruses. Signal Transduct. Target. Ther. 5, 89 (2020).

4. V. G. da Costa, M. L. Moreli, M. V. Saivish, The emergence of SARS, MERS and novel SARS-2 coronaviruses in the 21st century. Arch. Virol. 165, 1517-1526 (2020).

5. J. Cui, F. Li, Z. L. Shi, Origin and evolution of pathogenic coronaviruses. Nat. Rev. Microbiol. 17, 181-192 (2019)

6. A. J. Greaney, A. N. Loes, K. H. D. Crawford, T. N. Starr, K. D. Malone, H. Y. Chu, J. D. Bloom, Comprehensive mapping of mutations in the SARS-CoV-2 receptor-binding domain that affect recognition by polyclonal human plasma antibodies. Cell Host \& Microbe 29, 463-476.e466 (2021).

7. F. N. Release, Coronavirus (COVID-19) Update: FDA Authorizes Drug Combination for Treatment of COVID-19. FDA news (2020).

8. A. Shannon, N. T. T. le, B. Selisko, C. Eydoux, K. Alvarez, J. C. Guillemot, E. Decroly, O. Peersen, F. Ferron, B. Canard, Remdesivir and SARS-CoV-2: Structural requirements at both nsp12 RdRp and nsp14 Exonuclease active-sites. Antiviral Res. 178, -104793 (2020).

9. A. K. Singh, A. Singh, R. Singh, A. Misra, Remdesivir in COVID-19: A critical review of pharmacology, pre-clinical and clinical studies. Diabetes Metab. Syndr. 14, 641-648 (2020).

10. M. C. Genovese, J. S. Smolen, T. Takeuchi, G. Burmester, D. Brinker, T. P. Rooney, J. Zhong, M. Daojun, C. Saifan, A. Cardoso, M. Issa, W. S. Wu, K. L. Winthrop, Safety profile of baricitinib for the treatment of rheumatoid arthritis over a median of 3 years of treatment: An updated integrated safety analysis. Lancet Rheumatol. 2, e347-e357 (2020).

11. F. Wu, S. Zhao, B. Yu, Y. M. Chen, W. Wang, Z. G. Song, Y. Hu, Z. W. Tao, J. H. Tian, Y. Y. Pei, M. L. Yuan, Y. L. Zhang, F. H. Dai, Y. Liu, Q. M. Wang, J. J. Zheng, L. Xu, E. C. Holmes, Y. Z. Zhang, A new coronavirus associated with human respiratory disease in China. Nature 579, 265-269 (2020)

12. V. Tiwari, J. C. Beer, N. V. Sankaranarayanan, M. Swanson-Mungerson, U. R. Desai, Discovering small-molecule therapeutics against SARS-CoV-2. Drug Discov. Today 25, 1535-1544 (2020).

13. P. D. Nagy, J. Pogany, The dependence of viral RNA replication on co-opted host factors. Nat. Rev. Microbiol. 10, 137-149 (2012).

14. T. Hermann, Small molecules targeting viral RNA. Wiley Interdiscip Rev RNA 7, 726-743 (2016).

15. S. Fang, K. Li, J. Shen, S. Liu, J. Liu, L. Yang, C.-D. Hu, J. Wan, GESS: A database of global evaluation of SARS-CoV-2/hCoV-19 sequences. Nucleic Acids Res. 49, D706-D714 (2021).

16. M. Mukherjee, S. Goswami, Global cataloguing of variations in untranslated regions of viral genome and prediction of key host RNA binding protein-microRNA interactions modulating genome stability in SARS-CoV-2. PLOS ONE 15, e0237559 (2020).

17. T. C. T. Lan, M. F. Allan, L. E. Malsick, S. Khandwala, S. S. Y. Nyeo, M. Bathe, A. Griffiths, S. Rouskin, Structure of the full SARS-CoV-2 RNA genome in infected cells. bioRxiv 2020.2006.2029.178343, (2020).

18. A. Wacker, J. E. Weigand, S. R. Akabayov, N. Altincekic, J. K. Bains, E. Banijamali, O. Binas, J. Castillo-Martinez, E. Cetiner, B. Ceylan, L. Y. Chiu, J. Davila-Calderon, K. Dhamotharan, E. Duchardt-Ferner, J. Ferner, L. Frydman, B. Fürtig, J. Gallego, J. T. Grün, C. Hacker, C. Haddad, M. Hähnke, M. Hengesbach, F. Hiller, K. F. Hohmann, D. Hymon, V. de Jesus, H. Jonker, H. Keller, B. Knezic, T. Landgraf, F. Löhr, L. Luo, K. R. Mertinkus, C. Muhs, M. Novakovic, A. Oxenfarth, M. Palomino-Schätzlein, K. Petzold, S. A. Peter, D. J. Pyper N. S. Qureshi, M. Riad, C. Richter, K. Saxena, T. Schamber, T. Scherf, J. Schlagnitweit, A. Schlundt, R. Schnieders, H. Schwalbe, A. Simba-Lahuasi, S. Sreeramulu, E. Stirnal, A. Sudakov, J. N. Tants, B. S. Tolbert, J. Vögele, L. Weiß, J. Wirmer-Bartoschek, M. A. Wirtz Martin, J. Wöhnert, H. Zetzsche, Secondary structure determination of conserved SARS-CoV-2 RNA elements by NMR spectroscopy. Nucleic Acids Res. 48, 12415-12435 (2020).

19. I. Manfredonia, C. Nithin, A. Ponce-Salvatierra, P. Ghosh, T. K. Wirecki, T. Marinus, N. S. Ogando, E. J. Snijder, M. J. van Hemert, J. M. Bujnicki, D. Incarnato, Genome-wide mapping of SARS-CoV-2 RNA structures identifies therapeutically-relevant elements. Nucleic Acids Res. 48, 12436-12452 (2020).
20. N. C. Huston, H. Wan, M. S. Strine, R. C. A. Tavares, C. B. Wilen, A. M. Pyle, Comprehensive in vivo secondary structure of the SARS-CoV-2 genome reveals novel regulatory motifs and mechanisms. Mol. Cell 81, 584-598.e585 (2021).

21. B. Y. Alhatlani, In silicoidentification of conservedcis-acting RNA elements in the SARS-CoV-2 genome. Future Virol. 15, 409-417 (2020).

22. B.-J. Guan, Y.-P. Su, H.-Y. Wu, D. A. Brian, Genetic evidence of a long-range RNA-RNA interaction between the genomic $5^{\prime}$ untranslated region and the nonstructural protein 1 coding region in murine and bovine coronaviruses. J. Virol. 86, 4631-4643 (2012).

23. I. Sola, P. A. Mateos-Gomez, F. Almazan, S. Zuñiga, L. Enjuanes, RNA-RNA and RNA-protein interactions in coronavirus replication and transcription. RNA Biol. 8, 237-248 (2011).

24. K. Schubert, E. D. Karousis, A. Jomaa, A. Scaiola, B. Echeverria, L.-A. Gurzeler, M. Leibundgut, V. Thiel, O. Mühlemann, N. Ban, SARS-CoV-2 Nsp1 binds the ribosomal mRNA channel to inhibit translation. Nat. Struct. Mol. Biol. 27, 959-966 (2020).

25. L. O'Keefe. (FDA Press Announcements 2020).

26. T. Hermann, in RNA Therapeutics, A. L. Garner, Ed. (Springer International Publishing, Cham, 2018), pp. 111-134.

27. J. Davila-Calderon, N. N. Patwardhan, L. Y. Chiu, A. Sugarman, Z. Cai, S. R. Penutmutchu, M. L. Li, G. Brewer, A. E. Hargrove, B. S. Tolbert, IRES-targeting small molecule inhibits enterovirus 71 replication via allosteric stabilization of a ternary complex. Nat. Commun. 11, 4775 (2020).

28. G. Lozano, A. Trapote, J. Ramajo, X. Elduque, A. Grandas, J. Robles, E. Pedroso, E. Martínez-Salas, Local RNA flexibility perturbation of the IRES element induced by a novel ligand inhibits viral RNA translation. RNA Biol. 12, 555-568 (2015).

29. J. A. Kelly, A. N. Olson, K. Neupane, S. Munshi, J. San Emeterio, L. Pollack, M. T. Woodside J. D. Dinman, Structural and functional conservation of the programmed -1 ribosomal frameshift signal of SARS coronavirus 2 (SARS-CoV-2). J. Biol. Chem. 295, 10741-10748 (2020).

30. P. R. Bhatt, A. Scaiola, G. Loughran, M. Leibundgut, A. Kratzel, R. Meurs, R. Dreos, K. M. O'Connor, A. McMillan, J. W. Bode, V. Thiel, D. Gatfield, J. F. Atkins, N. Ban, Structural basis of ribosomal frameshifting during translation of the SARS-CoV-2 RNA genome. Science 372, 1306-1313 (2021).

31. S. Sreeramulu, C. Richter, H. Berg, M. A. Wirtz Martin, B. Ceylan, T. Matzel, J. Adam, N. Altincekic K. Azzaoui, J. K. Bains, M. J. J. Blommers, J. Ferner, B. Fürtig, M. Göbel, J. T. Grün, M. Hengesbach, K. F. Hohmann, D. Hymon, B. Knezic, J. N. Martins, K. R. Mertinkus, A. Niesteruk, S. A. Peter, D. J. Pyper, N. S. Qureshi, U. Scheffer, A. Schlundt, R. Schnieders, E. Stirnal, A. Sudakov, A. Tröster, J. Vögele, A. Wacker, J. E. Weigand, J. Wirmer-Bartoschek, J. Wöhnert, H. Schwalbe, Exploring the druggability of conserved RNA regulatory elements in the SARS-CoV-2 genome. Angew. Chem. Int. Ed. Engl. 60, 19191-19200 (2021).

32. H. S. Haniff, Y. Tong, X. Liu, J. L. Chen, B. M. Suresh, R. J. Andrews, J. M. Peterson, C. A. O'Leary, R. I. Benhamou, W. N. Moss, M. D. Disney, Targeting the SARS-CoV-2 RNA genome with small molecule binders and ribonuclease targeting chimera (RIBOTAC) degraders. ACS Central Sci. 6, 1713-1721 (2020).

33. D. J. Lefebvre, A. R. de Vleeschauwer, N. Goris, S. van Borm, A. Chimirri, A. M. Monforte, B. Valdazo-Gonzalez, D. P. King, J. Neyts, K. de Clercq, A thiazepino[4,5-a]benzimidazole derivative hampers the RNA replication of Eurasian serotypes of foot-and-mouth disease virus. Biochem. Biophys. Res. Commun. 455, 378-381 (2014).

34. C. S. Mugisha, H. R. Vuong, M. Puray-Chavez, A. L. Bailey, J. M. Fox, R. E. Chen, A. W. Wessel, J. M. Scott, H. H. Harastani, A. C. M. Boon, H. Shin, S. B. Kutluay, A Simplified quantitative real-time PCR assay for monitoring SARS-CoV-2 growth in cell culture. mSphere 5, e00658-20 (2020).

35. C. Richter, K. F. Hohmann, S. Toews, D. Mathieu, N. Altincekic, J. K. Bains, O. Binas, B. Ceylan, E. Duchardt-Ferner, J. Ferner, B. Fürtig, J. T. Grün, M. Hengesbach, D. Hymon, H. R. A. Jonker, B. Knezic, S. M. Korn, T. Landgraf, F. Löhr, S. A. Peter, D. J. Pyper, N. S. Qureshi, A. Schlundt, R. Schnieders, E. Stirnal, A. Sudakov, J. Vögele, J. E. Weigand, J. Wirmer-Bartoschek, K. Witt, J. Wöhnert, H. Schwalbe, A. Wacker, ${ }^{1} \mathrm{H},{ }^{13} \mathrm{C}$ and ${ }^{15} \mathrm{~N}$ assignment of stem-loop SL1 from the 5'-UTR of SARS-CoV-2. Biomol. NMR Assign. 15, 467-474 (2021).

36. R. Schnieders, S. A. Peter, E. Banijamali, M. Riad, N. Altincekic, J. K. Bains, B. Ceylan B. Fürtig, J. T. Grün, M. Hengesbach, K. F. Hohmann, D. Hymon, B. Knezic, A. Oxenfarth, K. Petzold, N. S. Qureshi, C. Richter, J. Schlagnitweit, A. Schlundt, H. Schwalbe, E. Stirnal, A. Sudakov, J. Vögele, A. Wacker, J. E. Weigand, J. Wirmer-Bartoschek, J. Wöhnert, ${ }^{1} \mathrm{H},{ }^{13} \mathrm{C}$ and ${ }^{15} \mathrm{~N}$ chemical shift assignment of the stem-loop 5 a from the $5^{\prime}$-UTR of SARS-CoV-2. Biomol. NMR Assign. 15, 203-211 (2021).

37. S. L. Wicks, A. E. Hargrove, Fluorescent indicator displacement assays to identify and characterize small molecule interactions with RNA. Methods 167, 3-14 (2019).

38. N. N. Patwardhan, Z. Cai, C. N. Newson, A. E. Hargrove, Fluorescent peptide displacement as a general assay for screening small molecule libraries against RNA. Org. Biomol. Chem. 17, 1778-1786 (2019).

39. Z. Miao, R. W. Adamiak, M. Antczak, R. T. Batey, A. J. Becka, M. Biesiada, M. J. Boniecki, J. M. Bujnicki, S. J. Chen, C. Y. Cheng, F. C. Chou, A. R. Ferré-D'Amaré, R. Das, W. K. Dawson, F. Ding, N. V. Dokholyan, S. Dunin-Horkawicz, C. Geniesse, K. Kappel, W. Kladwang, 
A. Krokhotin, G. E. Łach, F. Major, T. H. Mann, M. Magnus, K. Pachulska-Wieczorek, D. J. Patel, J. A. Piccirilli, M. Popenda, K. J. Purzycka, A. Ren, G. M. Rice, J. Santalucia Jr., J. Sarzynska, M. Szachniuk, A. Tandon, J. J. Trausch, S. Tian, J. Wang, K. M. Weeks, B. Williams II, Y. Xiao, X. Xu, D. Zhang, T. Zok, E. Westhof, RNA-puzzles round III: 3D RNA structure prediction of five riboswitches and one ribozyme. RNA 23, 655-672 (2017).

40. R. Rangan, I. N. Zheludev, R. Das, RNA genome conservation and secondary structure in SARS-CoV-2 and SARS-related viruses: A first look. RNA 26, 937-959 (2020).

41. W. M. Hewitt, D. R. Calabrese, J. S. Schneekloth Jr., Evidence for ligandable sites in structured RNA throughout the Protein Data Bank. Bioorg. Med. Chem. 27, 2253-2260 (2019).

42. R. P. Sheridan, V. N. Maiorov, M. K. Holloway, W. D. Cornell, Y. D. Gao, Drug-like density: A method of quantifying the "bindability" of a protein target based on a very large set of pockets and drug-like ligands from the Protein Data Bank. J. Chem. Inf. Model. 50, 2029-2040 (2010).

43. B. S. Morgan, J. E. Forte, A. E. Hargrove, Insights into the development of chemical probes for RNA. Nucleic Acids Res. 46, 8025-8037 (2018).

44. C. Iserman, C. Roden, M. Boerneke, R. Sealfon, G. M. Laughlin, I. Jungreis, C. Park, A. Boppana, E. Fritch, Y. J. Hou, C. Theesfeld, O. G. Troyanskaya, R. S. Baric, T. P. Sheahan, K. Weeks, A. S. Gladfelter, Specific viral RNA drives the SARS CoV-2 nucleocapsid to phase separate. bioRxiv 2020.2006.2011.147199, (2020).

45. E. J. Lefkowitz, D. M. Dempsey, R. C. Hendrickson, R. J. Orton, S. G. Siddell, D. B. Smith, Virus taxonomy: The database of the International Committee on Taxonomy of Viruses (ICTV). Nucleic Acids Res. 46, D708-D717 (2018).

46. S. F. Altschul, T. L. Madden, A. A. Schäffer, J. Zhang, Z. Zhang, W. Miller, D. J. Lipman Gapped BLAST and PSI-BLAST: A new generation of protein database search programs. Nucleic Acids Res. 25, 3389-3402 (1997)

47. K. Katoh, D. M. Standley, MAFFT multiple sequence alignment software version 7: Improvements in performance and usability. Mol. Biol. Evol. 30, 772-780 (2013).

48. J. B. Singer, E. C. Thomson, J. McLauchlan, J. Hughes, R. J. Gifford, GLUE: A flexible software system for virus sequence data. BMC Bioinformatics 19, 532-532 (2018).

49. A. M. Waterhouse, J. B. Procter, D. M. A. Martin, M. Clamp, G. J. Barton, Jalview Version 2--a multiple sequence alignment editor and analysis workbench. Bioinformatics 25, 1189-1191 (2009).

50. J. F. Milligan, O. C. Uhlenbeck, [5] Synthesis of small RNAs using T7 RNA polymerase. Methods Enzymol. 180, 51-62 (1989).

51. J. F. Milligan, D. R. Groebe, G. W. Witherell, O. C. Uhlenbeck, Oligoribonucleotide synthesis using T7 RNA polymerase and synthetic DNA templates. Nucleic Acids Res. 15, 8783-8798 (1987).
52. F. Delaglio, S. Grzesiek, G. W. Vuister, G. Zhu, J. Pfeifer, A. Bax, NMRPipe: A multidimensional spectral processing system based on UNIX pipes. J. Biomol. NMR 6, 277-293 (1995).

53. B. A. Johnson, R. A. Blevins, NMR view: A computer program for the visualization and analysis of NMR data. J. Biomol. NMR 4, 603-614 (1994).

54. W. Lee, M. Tonelli, J. L. Markley, NMRFAM-SPARKY: Enhanced software for biomolecular NMR spectroscopy. Bioinformatics 31, 1325-1327 (2015).

55. R. Abagyan, M. Totrov, D. Kuznetsov, ICM—A new method for protein modeling and design: Applications to docking and structure prediction from the distorted native conformation. J. Comput. Chem. 15, 488-506 (1994).

56. BioRender; https://app.biorender.com/biorender-templates (BioRender, 2020)

57. C. M. S. Singal, P. Jaiswal, P. Seth, SARS-CoV-2, More than a respiratory virus: Its potential role in neuropathogenesis. ACS Chem. Neurosci. 11, 1887-1899 (2020).

Acknowledgments: We are grateful for intellectual discussions and advice from A. Telisnitsky, S. Rouskin, N. Sherer, and C. Laudeman. Small molecules can be provided by A.E.H., pending scientific review and a completed material transfer agreement. Requests for the small molecules should be submitted to amanda.hargrove@duke.edu. Funding: We acknowledge funding from the following sources: NIGMS R35GM124785, Duke University to A.H.; NIGMS GM126833 to G.B. and B.T.; Tobacco Settlement Fund 21-5734-0010 to J.Y.; and Medical Research Council of the United Kingdom (MC_UU_12014/12) to R.J.G. Author contributions: Conceptualization: A.E.H., B.S.T., G.B., M.-L.L., S.B.K., A.W.T., and R.J.G. In vitro screening: M.-L.L., A.W.T., A.A.K., MZ., and C.S.M. NMR experiments: C.H., L.L., J.D.-C., and L.Y.-C. Computational analyses: J.D.Y., M.Z., A.G.M., and R.J.G. Supervision: G.B., B.S.T., A.W.T., S.B.K., and A.E.H. Writing (original draft): M.Z., C.H., and A.E.H. Manuscript editing: All. Competing interests: A.E.H., B.S.T., and G.B. are inventors on a pending patent application related to this work (U.S. provisional patent application no. 63/120,912, filed 3 December 2020). The other authors declare that they have no competing interests. Data and materials availability: All data needed to evaluate the conclusions in the paper are present in the paper and/or the Supplementary Materials. Supplementary Materials include additional figures and data related to OC43 screening, toxicity and qRT-PCR studies, NMR, docking, and small-molecule binding curves.

Submitted 26 July 2021

Accepted 6 October 202

Published 26 November 2021

$10.1126 /$ sciadv.abl6096 


\section{ScienceAdvances}

\section{Amilorides inhibit SARS-CoV-2 replication in vitro by targeting RNA structures}

Martina ZafferaniChristina HaddadLe LuoJesse Davila-CalderonLiang-Yuan ChiuChristian Shema MugishaAdeline G. MonaghanAndrew A. KennedyJoseph D. YesselmanRobert J. GiffordAndrew W. TaiSebla B. KutluayMei-Ling LiGary BrewerBlanton S. TolbertAmanda E. Hargrove

Sci. Adv., 7 (48), eabl6096. • DOI: 10.1126/sciadv.abl6096

View the article online

https://www.science.org/doi/10.1126/sciadv.abl6096 Permissions

https://www.science.org/help/reprints-and-permissions 